\title{
EVOLUÇÃO DAS BACIAS PROTEROZÓICAS E O TERMO-TECTONISMO BRASILIANO NA MARGEM SUL DO CRÁTON DO SÃO FRANCISCO
}

\author{
ANDRÉ RIBEIRO, RUDOLPH A. J. TROUW, RENATO R. ANDREIS, FÁBIO V. P. PACIULLO \& \\ JOEL G. VALENÇA
}

\begin{abstract}
EVOLUTION OF PROTERQZOIC BASINS AND THEIR BRASILIANO THERMALTECTONISM ALONG THE SOUTHERN MARGIN OF THE SÃO FRANCISCO CRÁTON Detailed mapping associated with the application of sequence stratigraphy, structural and petrographic analyses, permitted a reconstruction of the Meso to Neoproterozoic geológica evolution south of the craton. A major unconformity separates two main rock units, a pré $1.8 \mathrm{Ga}$ basement and its cover. The basement is composed of high grade gneisses, greenstpne belts and intrusives of variable composition. Four depositional cycles were recognised in the cover successions. In stratigraphic order these are: the Tiradentes and Lenheiro cycles, predominantly quartzitic, the Carandaí cycle with abundant pelites and carbonates, and the Andrelândia cycle with meta-sandstones and pelites. The analysis of these depositional cycles or sequences allowed the recognition of three depositional basins, the São João dei Rei basin, the Carandaí basin and the Andrelândia basin. The first two are intracontinental basins, whereas the last represents a passive continental margin of the São Francisco paleo-continent, that, at the time, extended futher southeast with relation to the present limit of the craton.

A continental collision around $600 \mathrm{Ma}$, here considered equivalent to the collision that resulted in the Brasília belt further north, produced extensive thrusting with nappe formation and top to the east tectonic transport. The associated metamorphism $\left(\mathrm{M}_{\mathrm{B}}\right)$ was of relatively high pressure type, as testified by the local occurrence of retro-eclogites. It reached the granulite facies in the stability field of kyanite. A second tectonic event, related to the Ribeira belt, at about $570 \mathrm{Ma}$, produced crustal shortening with tectonic transport to the NNW in the southern part of the region. The related metamorphism $\left(\mathrm{M}_{\mathrm{R}}\right)$, characterised by sillimanite and cordierite, is of lower pressure type and produced a large number of anatectic granite bodies. Finally, important NE-SW transpressive dextral shear zones were generated in response to renewed E-W shortening.
\end{abstract}

Keywords: Meso to Neoproterozoic basins, Neoproterozoic collisional tectonics

RESUMO Mapeamentos detalhados, associados a aplicação de conceitos da estratigrafia de sequências e análises estrutural e petrográfica, permitiram reconstruir a evolução geológica Meso- a Neoproterozoica no sul do craton. Uma discordância principal separa duas unidades maiores, um embasamento pré- $1.8 \mathrm{Ga}$ e a sua cobertura. $\mathrm{O}$ embasamento é composto por gnaisses de alto grau, faixas greenstone e intrusivas de variada composição. Na cobertura foram reconhecidos quatro ciclos deposicionais, denominados, em ordem estratigrafica, de Tiradentes, Lenheiro, Carandaí e Andrelândia. Os dois primeiros são predominantemente quartzíticos, o terceiro contém abundantes pelitos e calcários, e o último metarenitos e pelitos. A análise destes ciclos ou sequências deposicionais levou ao reconhecimento de três bacias deposicionais, as bacias São João dei Rei, Carandaí e Andrelândia. As duas primeiras são intracontinentais, enquanto a última representa uma margem continental passiva do paleocontinente do São Francisco, que na época se extendia mais para sudeste, em relação ao limite atual do craton.

Uma colisão continental ao redor de $600 \mathrm{Ma}$, aqui considerada como equivalente a que resultou na Faixa Móvel Brasília mais a norte, produziu extensivos empurrões com formação de nappes e transporte tectônico de topo para leste. O metamorrïsmo associado foi de pressão relativamente alta, evidenciado pela ocorrência local de retro-eclogitos e alcançou a facies granulito no campo de estabilidade da cianita. Um segundo episódio tectônico, relacionado a Faixa Móvel Ribeira, em torno de 570 Ma, produziu encurtamento crustal com transporte para NNW, na parte sul da região. O metamorfismo relacionado, caracterisado por sillimanita e cordieríta, foi de pressão mais baixa e produziu um grande numero de corpos graníticos anatéticos. Finalmente, importantes zonas de cisalhamento NE-SW, destrais, foram geradas em resposta a um renovado encurtamento E-W.

Palavras-chaves: Bacias Meso e Neoproterozóicas, tectônica colisioanal Neoproterozoica

INTRODUÇÃO Este trabalho sintetiza conhecimentos adquiridos pelos autores ao longo de 15 anos de pesquisas sobre as sucessões proterozóicas do sul de Minas Gerais, borda meridional do Craton do São Francisco (Fig. 1). Estas pesquisas deram continuidade aos levantamentos pioneiros realizados por Ebert $(1957,1971)$ e estão baseadas em mapeamentos detalhados acompanhados de análises estrutural, metamórfica e estratigráfica que, em conjunto, permitiram reconhecer a evolução termo-tectônica, a história paleoambiental e parte da paleografia proterozóica do sul mineiro. Se por um lado a geologia estrutural e metamórfica foram a base para o levantamento estratigráfico, por outro, a aplicação dos con- ceitos da estratigrafia de sequências (Mitchum et al. 1977, Van Wagoner et al 1990) ajudou a entender o complexo padrão estrutural e, inclusive, prever a possível distribuição das sequências reconhecidas além dos limites da região estudada.

Nesta região, sobre um embasamento com idade superior a $1.8 \mathrm{Ga}$, se desenvolveram duas bacias sedimentares intracontinentais mesoproterozóicas (Bacias São João dei Rei e Carandaí; Ribeiro, em preparação) e uma bacia de margem passiva neoproterozóica (Bacia Andrelândia; Paciullo et al. 1993). Eventos tectônicos extensionais foram responsáveis pela inversão e o consequente fechamento das duas bacias mais antigas, enquanto o evento termo-tectônico (ETT) multi- 


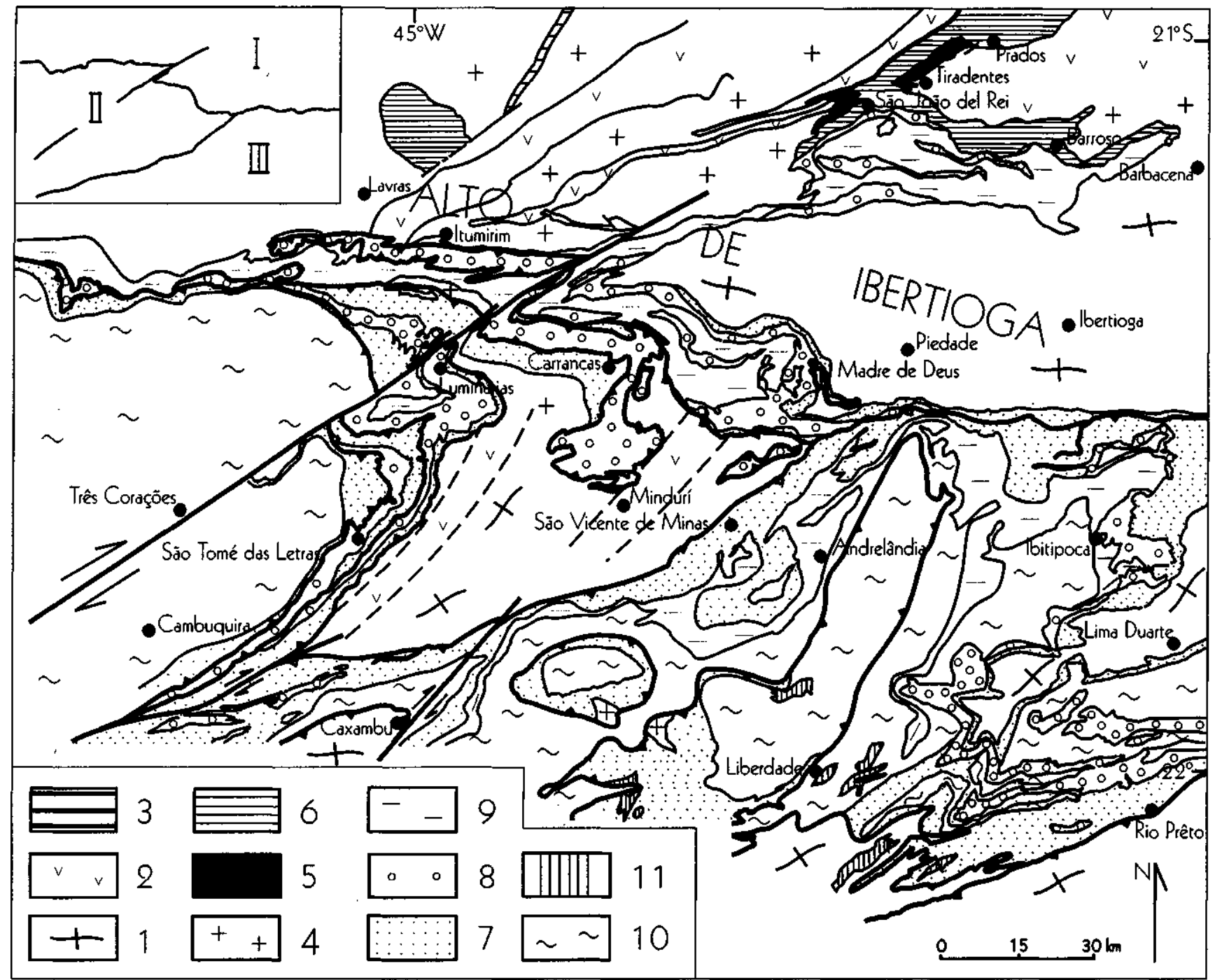

Figura l-Mapa geológico simplificado (baseado em levantamentos 1: 25.000 e 1: 50.000) Embasamento: l- Gnáisses de alto grau, 2- Faixas greenstone com intrusivasgranitóides e gabróicas, 3-Xistos, quartzitos, itabiritos (Supergrupo Minas), 4- Corpos granitóides e remanescentes de faixas greenstone, 5- Ciclos Deposicionais Tiradentes e Lenheiro, 6- Ciclo Deposicional Carandai; Ciclo Deposicional Andrelandia: 7- Paragnaisses, quartzitos, xistos e anfibolitos, 8- Quartzitos e xistos, 9-Biotitaxistos/gnaisses, 10- Associação de xistos, gnaisses, anfibolitos e rochas calcissilicatadas, 11- Rochas graniticas anatéticas Figure 1-Simplified geological map (based on 1:25.000 and 1:50.000 mapping) Basement: 1- High grade gneisses, 2- Greenstone belts with minor granitic and gabbroic intrusives, 3- Schists, quartzites, itabirites (Minas Supergroup), 4- Granitoid bodies with greenstone remnants, 5- Tiradentes and Lenheiro Depositional Cycles, 6- Carandaí Depositional Cycle; Andrelandia Depositional Cycle: 7- Paragneisses, quartzites, schists and amphibolites, 8- Quartzites e schists, 9Biotite-schists/gneisses, 10- Schists, gneisses, amphibolites and calc-silicate rocks, 11-Anatectic granites

episódico Brasiliano (680 - 450 Ma; intervalos segundo Almeida \& Hasui 1984), além de fechar a bacia mais nova, atingiu em grau variado as sucessões das bacias mais velhas e o próprio embasamento. Resultou um arcabouço tectônico que não se ajusta ao conceito de movimentos tectônicos simples, dirigidos para o cráton, nem aos limites convencionais do cráton brasiliano conforme proposto por Almeida (1977). Também não se ajusta ao modelo onde as sucessões proterozóicas consideradas e seu embasamento constituem um cinturão independente das faixas móveis brasilianas, ou seja, a Faixa Móvel Alto Rio Grande, conforme definida por Hasui \& Oliveira (1984) (cf. Trouw et al. 1994).

EMBASAMENTO (pré-1.8 Ga) Gnaisses de alto grau, faixas greenstone, corpos granitóides e gabróicos constituem o embasamento, de idade pré $1.8 \mathrm{Ga}$ (cf. Teixeira \&
Figueiredo 1991, Brito Neves 1992). Os gnaisses têm composição granodiorítica, tonalítica ou trondhjemítica e na maioria são rochas ortoderivadas, formando migmatitos de injeção, em parte modificados por anatexia e/ou granulitizados. Ocorrem ainda, intercalações de corpos anfibolíticos e ultramáfi$\cos$, de dimensões até métricas. Este conjunto gnáissico foi denominado de Grupo Mantiqueira (Barbosa 1954, Ebert 1957, Ebert 1971, Pires 1977) ou Complexo Mantiqueira (Brandalise et al. 1991) e inclui os granulitos da Suíte Metamórfica São Bento dos Torres definida por Pinto et al. (1992). Idades arqueanas foram obtidas em gnaisses semelhantes, próximos da região estudada (eg. Machado et al. 1983, Teixeira \& Figueiredo 1991, N. Machado et al. 1992).

As faixas greenstone, em conjunto denominadas de Greenstone Belt Barbacena por Pires (1978), tem orientação geral NE-S W (Fig. l) e são constituídas por sucessões supracrustais 
com variado grau de deformação e metamorfismo na facies xisto-verde ou epidoto-anfibolito. Contém rochas ultramáficas, máficas e félsicas, de origem vulcânica e subvulcânica, além de metassedimentos, nos quais os magmatitos se intercalam. As primeiras constituem corpos de composição toleítica ou komatiítica, em geral transformados em xistos verdes (Pires 1977, Noce 1987, Hoppe et al. 1984). Localmente apresentam feições primárias bem preservadas, como por exemplo estruturas do tipo spinifex (Teixeira 1992, J.G. Valença \& C.Avila, em preparação). Metasubvulcanitos riolíticos até riodacíticos, também com parcial preservação de texturas e estruturas primárias, constituem os corpos félsicos, até agora só conhecidos em São João dei Rei (Fig. 1). Nas sucessões metasedimentares predominam metapelitos cinzentos, maciços ou laminados, com intercalações de diferentes tipos de metachert (eg., gondito), metassiltitos e metawackes, além de escassos metadiamictitos. Provavelmente representam os depósitos de uma bacia desenvolvida acima dos terrenos gnáissicos, onde a sedimentação pelágica era interrompida por esporádicos fluxos de detritos e turbiditos associados (diamictitos, wackes, pelitos) e por periódicas efusões básicas e ultrabásicas. Ocorrem, ainda, alguns corpos quartzíticos transicionais a filitos, ambos cloríticos, provavelmente representando facies de borda de bacia. Ressaltamos que o estudo destas faixas greenstone ainda é incipiente e que não existem datações radiométricas de suas rochas. Rochas félsicas de cinturões semelhantes, reunidas no Supergrupo Rio das Velhas, a NE da região em foco, forneceram idades arqueanas (N. Machado et al. 1993).

Os granitóides constituem um conjunto de corpos intrusivos, graníticos, tonalíticos ou trondjhemíticos (Ávila 1992), com variada gnaissificação, aos quais se associam alguns tipos de metagabro. Pelo menos parte dos granitóides podem ter sua origem vinculada à fusão de gnaisses do Grupo Mantiqueira, como postulado por Ebert (1957, 1963) e Pires (1977). Possivelmente, este processo foi induzido pela introdução de magma básico na crosta, representado pelos metagabros. Estes granitóides e gabróicos podem ser ainda vinculados a pelo menos dois eventos de acreção crustal, por volta de 2.7 Ga e de 2.0 Ga (Cordani et al. 1973, Teixeira 1985, N. Machado et ai. 1993). Idades $\mathrm{Rb} / \mathrm{Sr}$ em rocha total relacionadas ao último evento, situam-se entre 1.95 e 2.0 Ga (Teixeira 1982, 1985, Heilbron et al. 1989, Trouw \& Pankhurst 1993). Uma idade U-Pb em zircão, de $1872 \pm 11$ Ma foi obtida por Söllner e Trouw (no prelo), reforçando o registro de um evento em torno de 2.0 Ma. Ainda no embasamento, ao sul de São João dei Rei, ocorrem gnaisses alcalinos de idade desconhecida (Ebert 1957, Coutinho 1968).

BACIAS PROTEROZÓICAS Discordantes sobre o embasamento ocorrem sucessões proterozóicas, deformadas e modificadas por metamorfismo devido ao Evento TermoTectônico Brasiliano (vide próximo capítulo). Os protólitos, tanto dos metassedimentos como de anfibolitos associados, ainda podem ser reconhecidos através de análises geoquímicas, petrográficas e principalmente nos afloramentos. $\mathrm{Na}$ maioria dos casos também é possível identificar características do acamamento e nos setores menos deformados (eg. São João dei Rei), o tipo e frequência de estruturas sedimentares. Deste modo, em função da interpretação dos protólitos, da identificação de discordâncias, de significativas mudanças litológicas e da atividade ígnea associada, Andreis et al. (1989a, b) e Ribeiro et al. (1990) reconheceram quatro ciclos deposicionais proterozóicos, de extensão regional, denominados, em ordem estratigráfica, de Tiradentes (CDT), Lenheiro (CDL), Carandaí (CDC) e Andrelândia (CDA). A análise destes ciclos ou sequências deposicionais possibilitou o reconhecimento de três bacias deposicionais (Fig.2), aqui denominadas São João dei Rei (BSJR), Carandaí (BC) e Andrelândia (BA, vide Paciullo et al. 1993). Na primeira depositaram-se as sucessões dos ciclos Tiradentes e Lenheiro, dominantemente quartzíticas. Nas outras duas a sedimentação está representada, respectivamente, pelos ciclos Carandaí (pelitos e calcários) e Andrelândia (arenitos e pelitos). Estas bacias desenvolveram-se entre 1,8 e 0,6 Ga, valores que representam as idades mais novas do embasamento e o primeiro episódio Brasiliano, respectivamente. Dados Sm-Nd (em preparação) indicam idades entre 1,8 e 1,3 Ga para diques máficos que cortam somente os CDT e CDL; e idades entre 1,15 e 1,0 Ga para efusivas máficas intercaladas em metapelitos do CDA. A provável correlação com as bacias do Espinhaço e São Francisco (Ribeiro \& Silva 1996), onde diques máficos forneceram idades em parte semelhantes (N. Machado et al. 1989), permite supor que a Bacia São João dei Rei se desenvolveu entre 1,8 e 1,3 Ga; a Bacia Carandaí entre 1,3 e 1,0 Ga e, finalmente, a Bacia Andrelândia entre 1,0 e 0,6Ga.

A sucessão de eventos tectônicos, ígneos, deposicionais e as correspondentes associações de litofacies em cada bacia será mostrada a seguir, seguindo um ordenamento estratigráfico. No caso da BA, estes eventos foram reconhecidos em domínios tectônicos distintos, autóctones ou alóctones (Fig. 1) (Ribeiro et al. 1990, Paciullo et al. 1993).

Bacia São João dei Rei Esta bacia, de caráter intracontinental, foi gerada por extensão e adelgaçamento crustal, porém, não existem evidências de um rifteamento inicial na região considerada. As rochas na BSJR ainda contém texturas e estruturas primárias preservadas, o que facilita o entendimento de sua história deposicional. Esta história começa com a invasão de um mar plataformal raso sobre embasamento desnudado e saprolitisado (Ribeiro et al. 1990), depois de um longo período de quiescência. $O$ processo transgressivo deu origem a sucessões quartzíticas depositadas em extensas rampas dominadas pela ação de correntes litorâneas e de marés. Estas sucessões alcançam até $450 \mathrm{~m}$ de espessura, abrangendo o CDT e a base do CDL. Posteriormente, este ambiente foi substituído por outros transicionais ou litorâneos, com formação de lagunas, barreiras e praias, representados na sucessão média do CDL, que atinge até $100 \mathrm{~m}$ de espessura. As paleocorrentes dominantes, produzidas por deriva litorânea, se orientavam para NE, paralelas a costa. Durante a persistência das condições plataformais ocorreram oscilações do nível do mar, gerando pelo menos duas discordâncias intraformacionais. A mais definida e de longa duração, marca a base do CDL. Estas discordâncias refletem períodos de instabilidade tectônica, precursores do rifteamento que provocou a progressiva substituição dos tratos de sistemas litorâneos por deposição em ambiente continental. A parte superior do CDL, com cerca de $400 \mathrm{~m}$ de espessura, mostra a instalação de um sistema fluvial entrelaçado distai (arenoso), que foi sendo substituído gradualmente, devido ao aumento da pendente regional, por facies proximais, com frequentes conglomerados. A composição destes ruditos (seixos de quartzo de veio, quartzitos e menor proporção de xistos e micas clásticas) e as paleocorrentes para o norte indicam levantamento e erosão das sucessões quartzíticas basais e do próprio embasamento, si- 

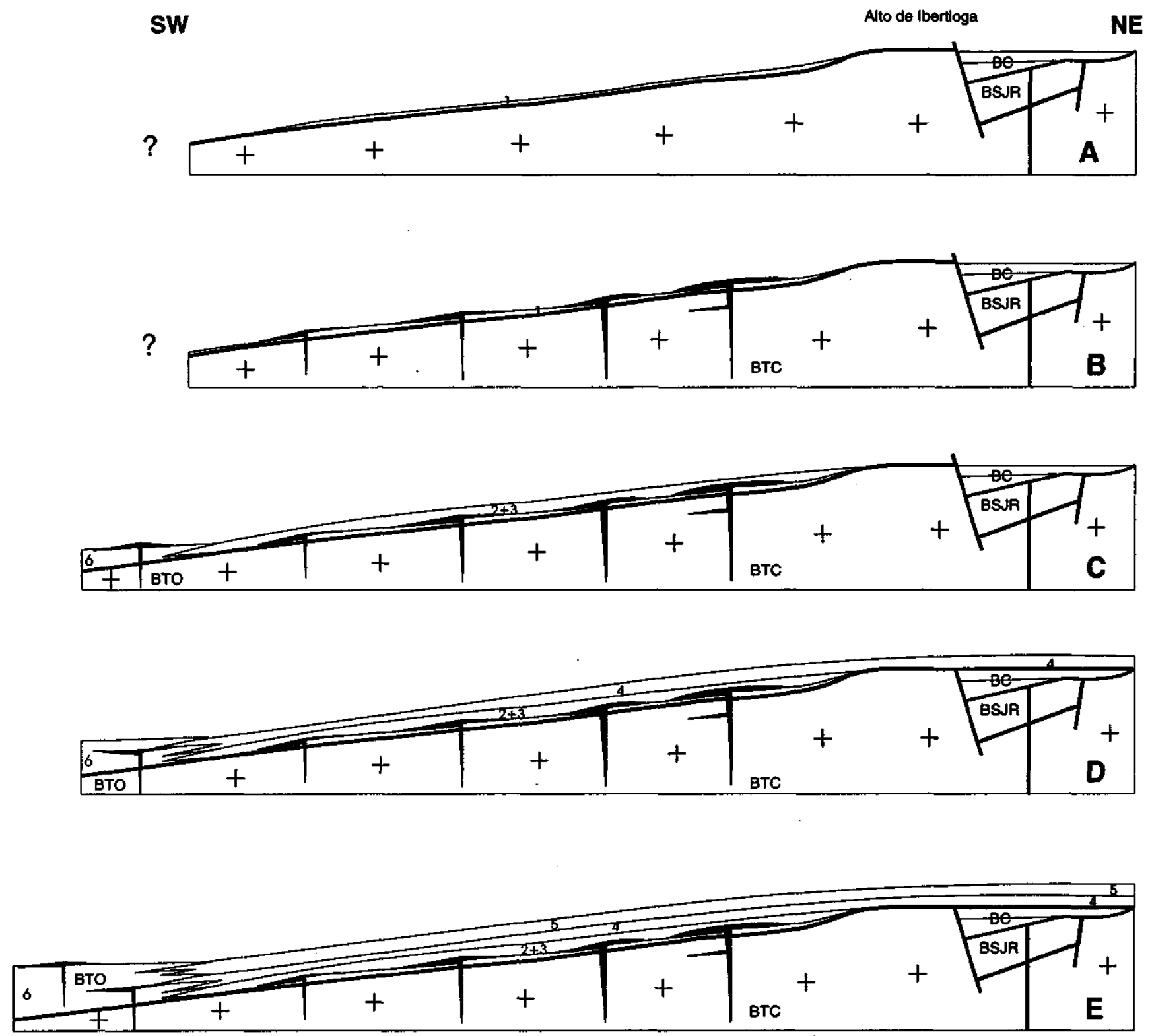

Figura 2 - Etapas de evolução da Bacia Andrelândia. l - Paragnaisses basais, 2 - Quartzitos e paragnaisses intercalados, 3 Quartzitos, 4 - Xistos cinzentos com intercalações de quartzitos, 5 - Biotita xistos, 6 - Xistos, gnaisses, anfibolitos e rochas calcissilicáticas; BC-Bacia Carandaí, BSJR - Bacia São João del Rei; BTO - Basaltos transicionais/oceânicos, BTC -Basaltos continentais; + - embasamento

Figure 2 - Evolution of the Andrelândia Basin. 1 - Basal paragneisses, 2 - Intercalations of quartzites and paragneisses, 3 - Quartzites, 4 - Gray schists with minor quartzite intercalations, 5 -Biotite-schists, 6 - Schists, gneisses, amphibolites and calc-silicate rocks, BTO - Transitional/oceanic basalts, BTC - Continental basalts, + - basement

tuados ao sul. Este soerguimento, causado por rifteamento, foi responsável pela progradação cada vez mais intensa do sistema fluvial, conduzindo ao posterior fechamento da BSJR. Após esta etapa, um novo processo distensivo, acompanhado pelo basculamento das sucessões antigas e intrusão de diques básicos de tendência alcalina, formou uma depressão elongada na direção NE-SW, com eixo subparalelo a borda da antiga bacia (BSJR). Esta depressão (meio-graben ?) mostra nova etapa de fragmentação na borda sul do proto-cráton do São Francisco e corresponde a parte funda de uma nova bacia.

Bacia Carandaí Á depressão supracitada favoreceu uma nova e rápida invasão marinha e a parcial redeposição dos detritos produzidos pelos processos de erosão subárea prévios. Estes depósitos formam uma sucessão com cerca de $1000 \mathrm{~m}$ de espessura, correspondente ao CDC. Apresentam-se pouco deformados e em baixo grau de metamorfismo (cf. Fig. 5). Com base na sua composição e distribuição regional eles podem ser separados em três associações de litofacies: A) pelitos, escassas margas e diamictitos, depositados na depressão, sobre as sucessões basculadas do CDT e CDL; B) calcários, margas e pelitos carbonáticos, depositados sobre pelitos de A e sobre o embasamento; C) pelitos com intercalações de quartzitos finos, restritos ao norte de Lavras (Fig. 1). Existe uma passagem gradativa entre as duas primeiras associações, mas a terceira aparece bruscamente sobre os calcários. 
Na associação A predominam siltitos arenosos ou argilosos, cinzentos, sericíticos e cloríticos, com variáveis proporções de quartzo e pirita. São laminados, gradados ou maciços e formam sucessões estratificadas de espessura até decamétrica. Os diamictitos contem seixos de quartzitos e quartzo de veio derivados da erosão das sucessões da BSJR e blocos de gnaisses e metabasitos do embasamento. Os pelitos foram depositados por correntes de turbidez diluídas ou por decantação na parte funda da bacia, os diamictitos por fluxos de detritos na borda da bacia.

A associação B inclui calcários cinza-azulados laminados ou maciços e transições para rochas pelíticas laminadas cinzentas, pretas e esverdeadas (margas, pelitos carbonáticos). Os calcáreos formam corpos contínuos de espessura decamétrica (Sinformal de Caetés e área de Barroso; Noce 1987) ou lenticulares de espessura métrica. Com frequência ocorrem ciclos decimétricos a métricos mostrando progressivo enriquecimento em carbonato (ciclos de pelitos carbonáticos-> marga->calcário), mas que também podem exibir diminuição lateral na proporção de carbonatos, especialmente nos corpos lenticulares (cf. Noce 1987). Esta associação representa condições de sedimentação tranquila acima do embasamento, em plataformas amplas e de pendente suave, onde a crescente precipitação de aragonita gerou os ciclos de pelitos carbonáticos e margas, que culminam com extensos mantos de calcário.

Ao norte de Lavras (Fig. 1), sobre os calcários, aparece a associação C, composta por um espesso pacote pelítico basal (cerca de $40 \mathrm{~m}$ ), sucedido por outro, também pelítico, mas que contém interestratificações de quartzitos finos em camadas tabulares delgadas a médias. Provavelmente os pelitos basais são equivalentes àqueles que ocorrem sobre os calcáreos nas regiões de São João dei Rei e Carandaí. Os pelitos da associação C mostram uma segunda subida do mar Carandaí, que talvez tenha se extendido mais ainda sobre o embasamento. Breves oscilações teriam produzido as intercalações quartzíticas (paraseqüências ?).

A abundância de facies pelíticas durante a sedimentação do CDC sugere a persistência de condições climáticas quentes e úmidas, que provocaram a argilização das rochas e a degradação quase total do relevo do embasamento. A presença dos calcários acima do embasamento indica a existência de plataformas cobertas por mar raso e de água quente. Delgados depósitos arenosos na interface entre o embasamento e pelitos sugerem discreta remoção dos materiais derivados do embasamento. A sedimentação tranquila e a ausência de atividade ígnea associada mostram que a evolução da Bacia Carandaí aconteceu durante um período de estabilidade tectônica.

Bacia Andrelândia Em comparação com as bacias São João dei Rei e Carandaí, a reconstrução da Bacia Andrelândia foi dificultada pela aloctonia das suas sucessões, como explicado no capítulo sobre o termo-tectonismo. No entanto, foi possível elaborar o seguinte modelo evolutivo. Após a litificação das sucessões do CDC, a reativação das falhas, que antes deram origem aos sistemas fluviais do CDL e ao graben Carandaí, provocaram novo soerguimento do embasamento a sul das antigas bacias (BSJR e BC). Nesta etapa houve uma mudança da pendente regional, de norte para sudoeste, marcando o estabelecimento da borda primitiva da Bacia Andrelândia. Aconteceram então novos processos de erosão do embasamento e a primeira deposição elástica na BA, representada pelos paragnaisses basais do CDA.
PARAGNAISSES BASAIS ("GNAISSINHO ") Apresentam-se em camadas lenticulares, delgadas a médias, constituindo sucessões de espessura até decamétrica. A composição quartzo-feldspática (plagioclásio e menor proporção de K-feldspato), a presença de escassos grânulos e seixos de plutonitos granodioríticos/tonalíticos e a assinatura geoquímica destes gnaisses (Paciullo, em preparação), permite interpretá-los como depósitos epiclásticos areníticos, derivados da erosão do embasamento. Considerando a evolução paleogeográfica da BA, a origem fluvial dos depósitos, como sugerida por Paciullo et al. (1993), parece a mais provável. Talvez representem vastas planícies de rios entrelaçados, com paleopendente para SW (Fig. 2A).

Associados aos paragnaisses ocorrem corpos lenticulares de espessura e extensão decimétrica a métrica, de ortoanfibolitos com afinidade toleítica continental (Paciullo 1992), que representam antigas efusões e/ou intrusões de magmas básicos (BTC, Fig. 2). Delgadas camadas ou mesmo lâminas, de anfibolitos e hornblenda-gnaisses intercaladas nos paragnaisses seriam produtos da erosão dos derrames de lavas. Este episódio magmático mostra uma fase de rifteamento incipiente, que promoveu o abatimento escalonado de blocos de embasamento a sul da borda da bacia (Fig. 2B). As áreas de embasamento a norte passaram a constituir um alto estrutural (cf. Paciullo et al. 1993), com orientação local W-E, aqui denominado de Alto de Ibertioga. Este rifteamento promoveu a primeira invasão marinha na BA, representado pela associação 2 do CDA (Fig. 2C).

QUARTZITOS E PARAGNAISSES INTERCALADOS Esta associação é composta por intercalações decimétricas a métricas de paragnaisses, quartzitos e menor proporção de xistos cinzentos (Fig. 2C), representando uma transição entre os paragnaisses basais (1) e os quartzitos sobrepostos (3), com progressivo enriquecimento em camadas quartzíticas para o topo. O conjunto é interpretado como resultado do avanço de um mar raso plataformal sobre os sedimentos fluviais, talvez associados a facies de maré e até pequenos deltas (?). Aparentemente a transgressão se deu através de oscilações do nível do mar, com formação de paraseqüências litorâneas num conjunto retrogradacional.

QUARTZITOS ("QUARTZITO MICA-VERDE") Aparecem sobre a associação anterior, constituindo pacotes com espessuras de até $50 \mathrm{~m}$ (3, Fig. 2C), que representam o estabelecimento de um mar raso em extensas plataformas de tipo rampa. Na parte para-autóctone do domínio tectônico III (vide termo-tectonismo), na região de Ibitipoca - Lima Duarte (Fig. 1), ocorrem facies proximais de acamamento espesso e granulometria grossa, inclusive com estruturas acanaladas. Elas foram depositadas sobre as associações litofaciais 1 e 2 e sobre o embasamento. Localmente, na área de Carrancas (domínio II, alóctone) ocorrem ortoconglomerados, com seixos de quartzo de veio e de quartzitos, provenientes da desnudação do embasamento. Facies de rampa distai afloram no setor de Luminárias - São Tomé das Letras (domínio II, alóctone) representadas por quartzitos com acamamento delgado, laminação e frequentes intercalações pelíticas. Os quartzitos gradam lateralmente para pelitos, em direção ao fundo da bacia, a SW (Fig. 2B). Esta sucessão quartzítica parece representar um conjunto agradacional de paraseqüências, desenvolvido durante um evento de mar baixo. 
XISTOS CINZENTOS COM ESCASSAS INTERCALACCÕES DEQUARTZITOS("MISTO") Nos domínios II e III, aparece uma sucessão predominantemente pelítica, depositada acima da rampa definida pela associação 3 . No setor de rampa distai (Luminárias, São Tomé das Letras) só ocorrem pelitos, mas acima da rampa proximal (eg., Carrancas) ocorrem camadas de quartzitos intercaladas nos pelitos (xistos cinzentos). Em conjunto, estas sucessões podem ser interpretadas como resultado de um brusco ascenso do nível do mar acima da rampa. A evolução do processo transgressivo está bem caracterizado em Carrancas, onde podem ser definidas duas etapas de subida brusca do nível do mar com deposição de pelitos, separadas por discretas oscilações, representadas pelas intercalações quartzíticas (paraseqüências mostrando fraca retrogradação).

Provavelmente, durante a segunda etapa de subida do mar as áreas continentais ao norte do Alto de Ibertioga foram inundadas, resultando na deposição de pelitos e reduzidas facies heterolíticas e arenosas, sobre sucessões da Bacia Carandaí (Fig. 2D). O acamamento delgado, as cores cinzentas, a ocorrência de pirita e grafita, sugerem deposição em ambiente lagunar, parcialmente fechado (condições euxínicas). A presença de grãos de plagioclásio (Valeriano 1985, Noce 1987) indica aporte do embasamento próximo (Alto de Ibertioga?).

BIOTITA-XISTO/GNAISSE Constituem sucessões com dezenas a centenas de metros de espessura, de xistos homogéneos ou com intercalações de outras litologias. Nestas últimas, localizadas na faixa autóctone entre Madre de Deus e Itumirim (domínio I; Fig. 1), os xistos contêm lentes de meta-wackes grossas, quartzo-líticas (Heilbron 1984), quartzitos delgados (Ribeiro 1980), meta-arenitos feldspáticos e até seixos e matacões dispersos ou formando metadiamictitos. Os fragmentos são de rochas plutônicas (granitóides), metamórficas (calcio-silicáticas) e quartzo de veio. Este conjunto de litofacies aparece logo acima da associação anterior (4) e, provavelmente, foi depositado em aprons, localizados nas vizinhanças do continente (Alto de Ibertioga), com participação de correntes de turbidez diluídas, fluxos de detritos e blocos pingados. Estes depósitos podem ter origem glaciomarinha, sugerindo a existência de um período glacial, com geleiras acima do Alto de Ibertioga ou em regiões mais distantes, localizadas ao norte. Neste sentido, é muito provável a equivalência com os tilitos associados a estrias, descritos no Grupo Macaúbas (Isotta et al. 1969, Hettich 1977), que representam deposição sub-glacial em um centro de dispersão de geleiras. A sedimentação glacio-marinha caracteriza uma segunda fase de mar baixo na BA.

Os biotita-xistos mais homogéneos aparecem a sul e sudoeste (domínios II e III; Fig. 1), na parte mais funda da bacia e, provavelmente, representam turbiditos que se intercalam com facies da associação 6 (Fig. 2E). Recobrem também os depósitos glacio-marinhos, evidenciando subida glacio-eustática do mar, ocorrido após a glaciação. Este ascenso do mar está registrado ao norte do Alto por xistos listrados, cujos protólitos são prováveis ritimitos lagunares e/ou estuarinos.

ASSOCIAÇÃO DE XISTOS, GNAISSES, ANFIBOLITOS E ROCHAS CALCISSILICATADAS Restrita aos domínios II e III, representa sedimentação pelágica e turbidítica que ocorreu na parte mais funda da bacia. Os depósitos estão agora representados por espessas sucessões de xistos e gnaisses, homogéneos ou com acamamento delgado a médio. Aparecem ainda outras facies pelíticas (correspondentes às associações 2 e 3 ) e turbidíticas (4 e 5). Os anfibolitos têm natureza toleítica transicional e oceânica (Gonçalves \& Figueiredo 1992, Paciullo 1992) e são interpretados como produto de derrames submarinos e intrusões nos depósitos de fundo da bacia. As rochas calcio-silicáticas geralmente ocorrem associadas aos anfibolitos. Ainda no domínio III, a noroeste de Caxambu, a associação 6 aparece normalmente acima do embasamento (Oliveira Castro, mestrado em andamento, UFRJ).

\section{EVENTO TERMO-TECTONICO BRASILIANO}

Este evento está registrado nas sequências deposicionais proterozóicas e no seu embasamento de forma multi-episódica. Gerou falhas de empurrão e dobramentos sucessivos, além de zonas de cisalhamento subverticais e dois tipos de metamorfismo, o mais velho de pressão relativamente alta, seguido por outro de pressão mais baixa. Em conjunto, estas feições tectônicas e metamórficas representam a interferência entre uma colisão precoce, de $\mathrm{W}$ para $\mathrm{E}$, envolvendo empurrão do maciço do Guaxupé em direção ao proto-craton do São Francisco, situado a leste e um encurtamento crustal subsequente, E-W, que gerou empurrões no sentido SSE-NNW e zonas de cisalhamento NE-SW. O primeiro episódio é aqui relacionado a colisão que produziu a Faixa Móvel Brasília, o segundo a tectônica que resultou na Faixa Móvel Ribeira.

Para melhor compreensão das estruturas tectônicas nesta zona de interferência, a região considerada foi dividida em três domínios distintos, um autóctone (I) e dois alóctones (II, III) (Ribeiro et al. 1990). No entanto, o domínio III pode ainda ser dividido em sub-domínio da Nappe de Liberdade e subdomínio para-autoctóne (Fig. 3). Como no domínio II as estrututras do primeiro tectonismo estão melhor preservadas, será abordado primeiro.

\section{Estruturas relacionadas a Faixa Movei Brasília}

Domínio II As macro e microestruturas neste domínio foram descritas por Trouw et al. $(1980,1982,1983,1984)$, Ribeiro (1980), Paciullo (1980), Heilbron (1984), Maciel (1985), Chrispim (1983) e Almeida (1992). Relacionam-se com bastante nitidez a colisão que produziu transporte tectônico de W para E, gerando uma sucessão de nappes $\mathrm{e}$ escamas empurradas, estruturadas num sinformal suave com eixo de caimento para oeste (Fig. 3). A deformação foi dúctil e penetrativa e o movimento principal coincidiu aproximadamente com o auge do metamorfismo, de maneira que poucos milonitos ficaram preservados (Trouw et al. 1980, 1982, 1984). Deste modo, as superficies marcadas no mapa como falhas de empurrão foram definidas principalmente pelo truncamento ou repetição de unidades estratigraficas, pela presença de lentes do embasamento entre metassedimentos, além de pulos metamórficos. Entretanto, o movimento cisalhante não ficou restrito a estas superfícies de empurrão. Distribuiuse através dos pacotes metassedimentares e parte do embasamento (Hatcher \& Hooper 1992), deixando vestígios na forma de SL tectonitos, com forte lineação de estiramento de caimento suave para oeste (Fig. 3), além de dobras fechadas a isoclinais, geralmente com eixos paralelos a lineação de estiramento. As micro, meso e macro dobras, tem vergência tanto para norte como para sul. A maioria destas dobras se formaram com eixos subparalelos a direção de movimento 


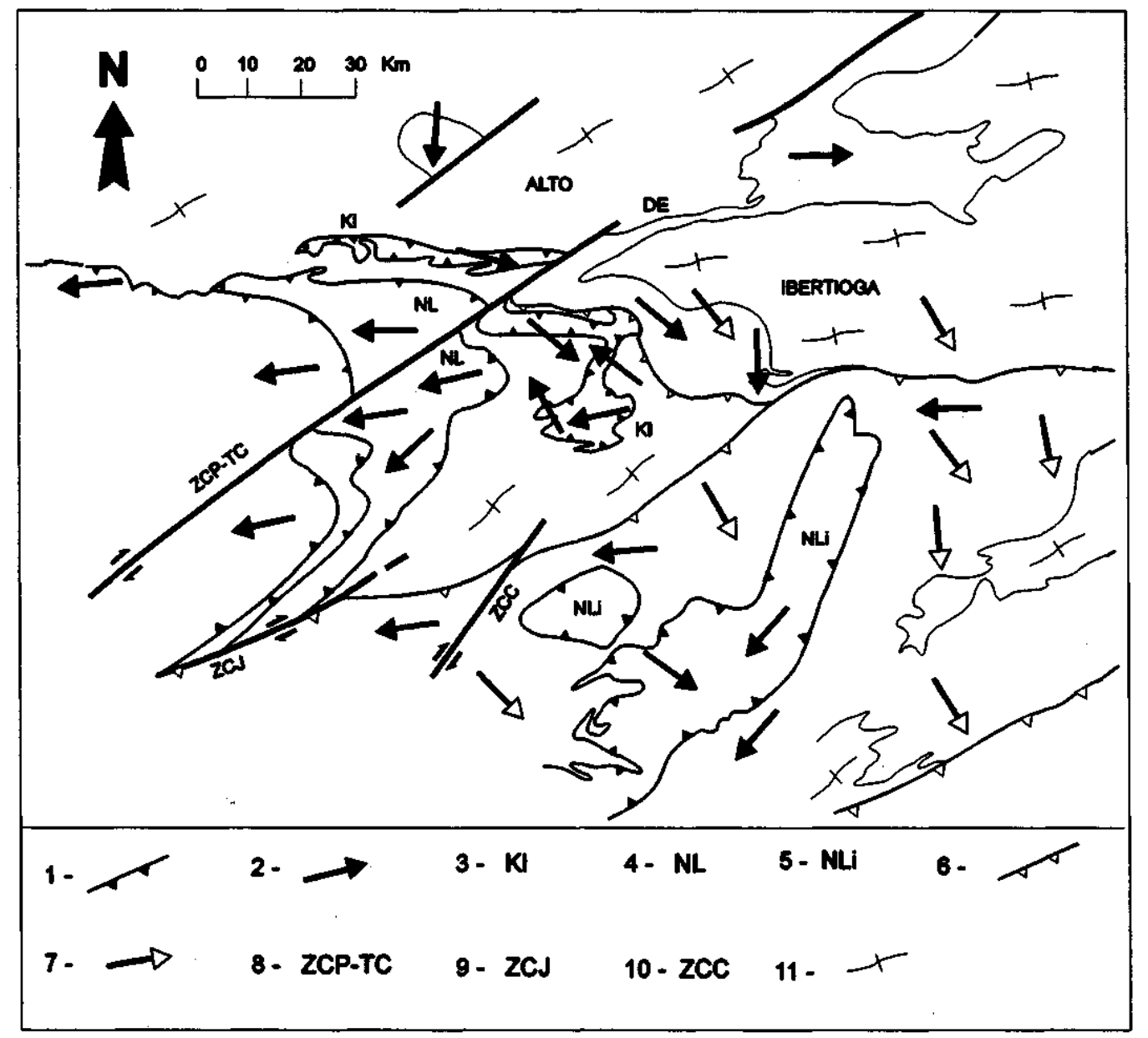

Figura 3 - Mapa simplificado mostrando as principais feições estruturais. Tectônica relacionada a Faixa Móvel Brasília: 1 - falhas de empurrão; 2 - lineação de estiramento; 3 - klippe Itumirim-Carrancas-Minduri; 4 - nappe de Luminárias; 5 - nappe de Liberdade. Tectônica relacionada a Faixa Móvel Ribeira: 6 - falhas de empurrão; 7 - lineação de estiramento; Zonas de Cisalhamento: 8 - Pombeiro-Três Corações; 9 - Jesuânia; 10 - Caxambu; 11 - embasamento

Figure 3 - Simplified map, showing the principal structural features. Tectonics related to the Brasília Mobile Belt: 1- Thrust faults; 2 - Stretching lineàtion; 3 - Itumirim-Carrancas-Minduri klippe; 4 -Luminárias Nappe; 5 - Liberdade Nappe. Tectonics related to the Ribeira Mobile Belt: 6 - Thrust faults; 7 - Stretching lineàtion; Shear Zones: 8 - Pombeiro Três Corações; 9 - Jesuânia; 10 - Caxambu. 11 - basement

(W-E), devido ao confinamento entre rampas laterais convergentes (Almeida 1992) ou ao processo de geração de dobras obliquas (Passchier et al. 1992). Localmente foram reconhecidas dobras em bainha (sensu Cobbold \& Quinquis 1980), demonstrando também a viabilidade de um processo de encurvamento progressivo dos eixos de dobras durante a deformação (Trouw et al. 1982, Maciel 1985).

Estruturas de interferência, como redobramentos, clivagem de crenulação e lineações dobradas, permitiram a caracterização de duas fases de deformação, provavelmente contínuas, em trabalhos anteriores denominadas de $\mathrm{D}_{1}$ e $\mathrm{D}_{2}$ (eg. Trouw et al. 1982). Estas duas fases são relacionadas a tectônica da Faixa Móvel Brasília e aqui renomeadas $D_{\mathrm{B} 1}$ e $\mathrm{D}_{\mathrm{B} 2}$. Em conjunto $\mathrm{D}_{\mathrm{B} 1}$ e $\mathrm{D}_{\mathrm{B} 2}$ serão referidos como $\mathrm{D}_{\mathrm{B}}$, em alusão a Faixa Móvel Brasília.

As evidências para o sentido de movimento tectônico, de topo para leste, são lentes micaceas assimétricas em quartzitos (Fig. 4a), planos S-C e C' (Passchier \& Trouw, no prelo) que mesmo parcialmente mascarados por recristalização, ainda mostram o sentido de movimento tectônico. As primeiras são frequentes em quartzitos na área de Luminárias, enquanto os planos $\mathrm{S}-\mathrm{C}$ e $\mathrm{C}^{\prime}$ são mais frequentes nos gnaisses da área de Lambari (Oliveira Castro \& Trouw, no prelo). Além do mais, as fatias tectônicas acunham para oeste, com as orientações dos seus branch Unes na posição norte-sul reforçando o sentido de movimento para leste (Fig. 3).

Ainda no domínio II, Paciullo (trabalho em andamento) definiu a klippe Itumirim-Carrancas-Minduri (Fig. 3). Tratase de uma fatia de metassedimentos empurrada sobre o domínio autóctone, cujo movimento tectônico, de WNW paraESE, atribuído a $\mathrm{D}_{\mathrm{B} 1}$, é indicado por forte lineação de estiramento em quartzitos e seixos estirados de conglomerados, além de granadas rotacionais (Fig. 4b). Esta klippe, considerada como um relicto da Nappe de Passos (Simões 1995, vide também Valeriano 1992), foi ainda dobrada num sinformal fechado, com eixo variando de W-E até NW-SE, devido a superimposição do movimento W-E ( $\left.\mathrm{D}_{\mathrm{B} 2}\right)$, da Nappe de Luminárias.

Domínio I Aqui as sequências metassedimentares encontram-se em sua posição original e em lugar de falhas de empurrão, foram reconhecidas as discordâncias mencionadas no capitulo anterior. Portanto, o domínio I é considerado autóctone, apesar do nítido aumento da deformação em direção sudeste. Assim, nos setores menos deformados os eixos de dobras permanecem a um angulo grande com a direção de encurtamento máximo. Mas de São João del Rei para sudeste 
as dobras ficam cada vez mais mais fechadas e seus eixos giram desde a direção ENE para ESE. As lineações de estiramento, só desenvolvidas nas áreas de deformação mais intensa, também caem para ESE (Valeriano 1985, Noce 1987). Este giro foi interpretado como resultado da rotação dos eixos de dobras, originalmente perpendiculares a direção de encurtamento principal, no caso WNW, para uma posição paralela a esta direção (Noce 1987). Veios assimétricos de calcita (tension gashes) em metacalcareos indicam o mesmo sentido de movimento, de topo para WNW. Este movimento, atribuído a $\mathrm{DB}$, foi provavelmente contemporâneo com o da Nappe de Passos, pois suas direções coincidem, embora os sentidos sejam opostos.

Nos metassedimentos da Bacia Carandaí a norte de Lavras (Fig. 1) as lineações têm caimento para sul, com indicadores cinemáticos de transporte de topo para norte. O confinamento lateral vinculado aos empurrões $\mathrm{D}_{\mathrm{B} 2}$, poderia, explicar este movimento.

Domínio III Aqui o padrão tectônico resulta da interferência entre empurrões DB e estruturas mais novas, incluindo empurrões paraNNW e zonas de cisalhamento transpressivas, NE-SW, relacionados a Faixa Móvel Ribeira. A repetição estratigráficade unidades do Ciclo Deposicional Andrelândia, associada a presença de lentes do embasamento (Silva 1990) caracteriza a estrutura chave deste domínio -a Nappe de Liberdade, uma estrutura atribuida a $\mathrm{D}_{\mathrm{B}}$ (Fig. 3). O movimento desta nappe, para NE, foi deduzido a partir de granadas snow ball (Fig. 4c), planos $C^{\prime}$ em gnaisses miloníticos, veios de quartzo assimétricos em padrão de planos S-C (Fig. 4e) e peixes assimétricos de cianita. $\mathrm{O}$ cisalhamento dúctil dentro da nappe, gerou também dobras $\mathrm{D}_{\mathrm{B} 1}$ e $\mathrm{D}_{\mathrm{B} 2}$ (Gonçalves 1987, Bittar 1989, Silva 1990, Nummer 1991), com características semelhantes às do domínio II. Um exemplo é a dobra em bainha, macroscópica, a S W de Aiuruoca (Junho et al. 1991).

CORPOS ULTRAMÁFICOS Uma centena de corpos ultramáficos, com diâmetros desde métricos até $\sim 2 \mathrm{~km}$, ocorrrem encaixados em xistos e gnaisses ao longo de zonas de empurrão DB. Apresentam composição mineralógica variada, incluindo dunito, espinélio-harzburgito, ortopiroxenito, websterito, serpentinito, e rochas quase exclusivamente compostas de anfibólio, clorita ou talco (Magalhães 1985, S. Almeida 1992). Segundo S. Almeida (1992), as associações mineralógicas metamórficas indicam parcial reequilíbrio em condições de 600 até $800^{\circ} \mathrm{C}$ e pressões entre 10 e $20 \mathrm{kbar}$, além de retro-metamorfismo em temperaturas mais baixas. Esta autora concluiu também que a composição química e mineralógica sugere origem crustal, a partir de cristalização fracionada de magmas toleíticos. No entanto, o modo de ocorrência destes corpos, isolados e associados às falhas de empurrão profundas, que inclusive envolvem granulitos de alta pressão e eclogitos (ver a seguir) e a falta de gradações para rochas máficas, apontam para uma origem mantélica, ainda que não necessariamente ofiolítica. Estes corpos podem representar o manto litosférico sob a crosta continental adelgaçada. Corpos ultramáficos semelhantes, ao longo da falha de empurrão na região de Jacuí (Fig. 5), foram interpretados por Roig \& Schrank (1992) como possíveis fragmentos de ofiolitos, numa sutura brasiliana, vinculada a colisão continental com vergência para leste.

Metamorfismo Abrange a facies xisto verde médio até a facies anfibolito alto, localmente atingindo a facies granulito
(Fig. 5). A presença de cianita e sillimanita levou a interpretação original que a série de facies metamórficas corresponderia às do tipo barroviano clássico (e.g. Ebert 1971, Trouw et al. 1984, 1986). Entretanto, o mapeamanto de isógradas, associado a estudos microtectônicos, evidenciaram a existência de dois metamorfismos, parcialmente superpostos. O primeiro, $M_{B}$, caracteriza-se pela presença de cianita, estável até a facies granulito, onde coexiste com K-feldspato; não desenvolveu sillimanita e por tal razão pertence a uma série de facies de pressão mais elevada que a série barroviana. $M_{B}$ esta presente na Nappe de Passos, no sistema de nappes de Luminárias e, de forma reliquiar, na Nappe de Liberdade (Fig. 3). Por tal razão vincula-se ao termo-tectonismo da Faixa Móvel Brasília. $\mathrm{O}$ segundo metamorfismo, $\mathrm{M}_{\mathrm{R}}$, de pressão mais baixa, caracteriza-se por sillimanita e localmente cordierita na facies anfibolito. Superpõe-se ao $\mathrm{M}_{\mathrm{B}}$ na parte sul da área (Fig. 5) e é interpretado como relacionado a Faixa Móvel Ribeira.

METAMORFISMO $M_{B}$ Trouw et al. (1980, 1984, 1986) e Heilbron $(1984,1985)$ descreveram este metamorfismo em detalhe na região entre Lavras, São João dei Rei, Lima Duarte, Liberdade e Três Corações (Fig. 5). Estes estudos serviram de base para interpretações nas outras áreas. $\mathrm{M}_{\mathrm{B}}$ aumenta de grau desde São João dei Rei para sudoeste. Na zona de mais baixo grau as rochas pertencem a facies xisto verde médio, com biotita em rochas pelíticas de composição apropriada e, localmente, com cloritóide e cianita em quartzitos. A sul aparecem as isógradas da granada e estaurolita em rochas pelíticas (Heilbron 1984, 1985, Trouw et al. 1986). A última marca a entrada na facies anfibolito e coincide, aproximadamente, com a saída de cloritóide e a entrada de cianita em metapelitos. A partir destas isógradas coexistem cianita, granada, biotita e muscovita, em facies anfibolito, até a região de Liberdade. Na nappe de Liberdade (Fig. 3), da base para topo, existe uma transição da facies anfibolito para facies granulito, definida pelas isógradas de K-feldspato-in e muscovita-out, em rochas metapelíticas com cianita (Oliveira Castro \& Barone 1994). Estas isógradas caracterizam a reação muscovita + quartzo $=$ $\mathrm{k}$-feldspato + cianita $+\mathrm{H}_{2} \mathrm{O}$, gerando cianita-granulitos de uma série de facies metamórfica de pressão mais alta que a série barroviana clássica. Corpos máficos intercalados ontêm clinopiroxênio + granada + plagioclásio + anfibólio, associação também típica de granulitos de alta pressão. Estas rochas máficas apresentam intercrescimentos simplectíticos entre anfibólio e plagioclásio ao redor de granada (Silva 1990), característicos de retrometamorfísmo em rochas de alto grau (Yardley 1989).

Cianita-granulitos com k-feldspato ocorrem também ao sul de Caxambu (M. Junho e M. Monteiro, informação pessoal) e entre Três Corações e Jacuí (Fig. 5). Geotermobarometria realizada nos granulitos máficos de Liberdade indicou temperaturas entre $800^{\circ}$ e $900^{\circ} \mathrm{C}$ e pressões entre 12 e $13,5 \mathrm{kbar}$ (Trouw, dados inéditos). Na área de Jacuí, Del Lama et al. (1993) utilizando a mesma metodologia, chegaram a conclusão que houve dois intervalos para as condições metamórficas: $830^{\circ}-900^{\circ} \mathrm{C}$ com $12,5-15 \mathrm{~kb}$ e $700^{\circ}-750^{\circ} \mathrm{C}$ com 11,8 $-12,1 \mathrm{~kb}$, ambos no campo da estabilidade de cianita. Simões (1995), mostrou que na Nappe de Passos o metamorfismo também aumenta da base para o topo, com as condições PT máximas de $11 \mathrm{~kb}$ e $750^{\circ} \mathrm{C}$, correspondendo ao limite inferior da facies granulito, na presença de cianita. $\mathrm{O}$ caráter de pressão relativamente alta de $\mathrm{M}_{\mathrm{B}}$ é acentuado ainda pela presença de retro-eclogitos, encontrados entre Andrelândia, Liberdade e 

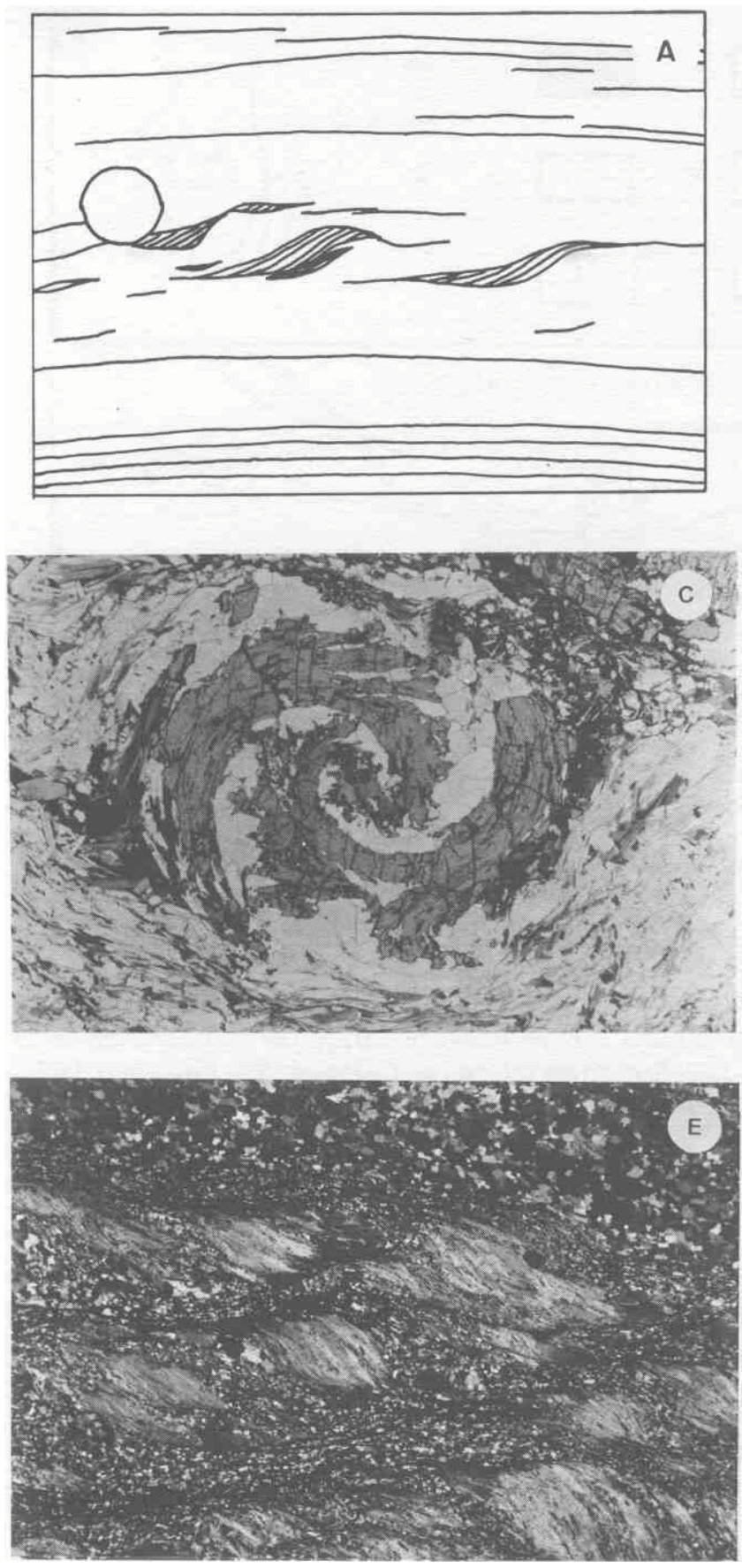
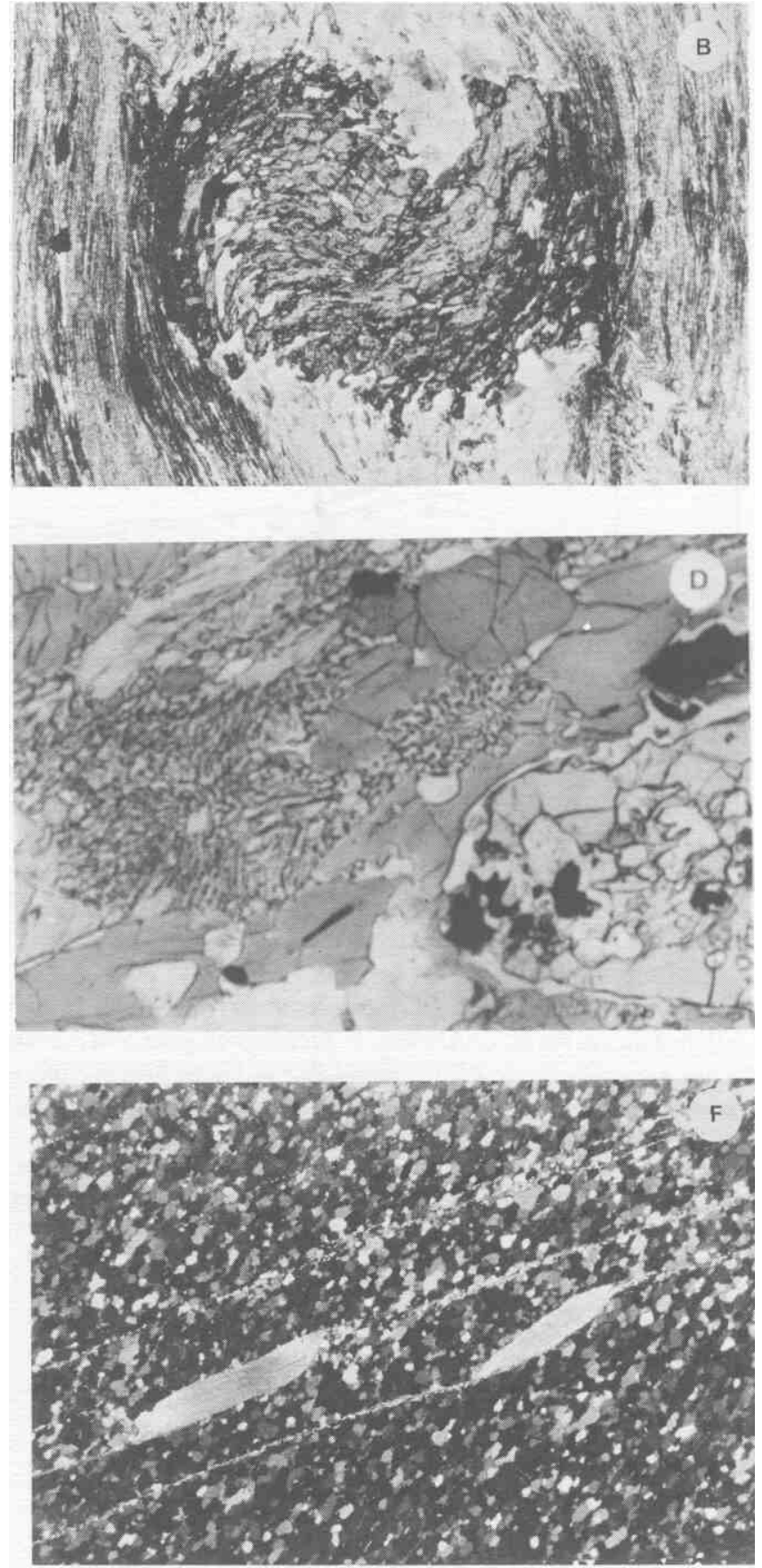

Figura 4 - a) Lentes micáceas assimétricas em quartzito, indicativas de cisalhamento do topo para leste; $2 \mathrm{~km}$ ESE de Luminárias; desenho sobre fotografia; b) Granada sintectônica mostrando um giro relativo a foliação de - $120^{\circ}$ no sentido destral; polarizadores a 45; diâmetro da granada $\sim \mathrm{lmm}$; xisto a $3 \mathrm{~km}$ SE de Itumirim; c) Granada sin-tectônica do tipo snowball com giro destral em relação a foliação circundante de no mínimo $360^{\circ}$; NX; diâmetro da granada $\sim 5 \mathrm{~mm}$; gnaisse a $30 \mathrm{~km}$ a leste de Caxambu; d) Retro-eclogito com granada (parte inferior a direita), anfibólio verde/marrom (cristais cinzas na foto) e intercrescimento simplectítico entre diopsídio e plagioclásio; notar a corona estreita de plagioclásio ao redor da granada; NX; campo visual l mm; $15 \mathrm{~km}$ a SE de Andrelândia; e) Planos $S$-C e peixes assimétricos de foliação em quartzo-mica-xisto, indicando sentido de cisalhamento sinistrai; $\mathrm{NX}$; campo visual Wmm; $10 \mathrm{Km}$ a $\mathrm{N}$ de Ibitipoca; f) Peixes assimétricos de mica em milonito; o movimento destral também é indicado pelo stair stepping e pela petrotrama obliqua do quartzo; zona de cisalhamento de Jesuania (Fig. 3)

Figure 4- a) Asymmetric micaceous lenses in quartzite, indicating top to the east sense of shear; $2 \mathrm{~km}$ ESE of Luminárias; traced from photograph. b) Syntectonic garnet showing dextral rotation relative to the surrounding foliation of $\sim 120^{\circ}$; polarisers at $45^{\circ}$; diameter of garnet $\sim 1 \mathrm{~mm}$; schist, $3 \mathrm{~km}$ SE of Itumirim. c) Syntectonic snowball garnet showing at least $360^{\circ}$ dextral rotation with respect to the surrounding foliation; PPL; diameter of garnet $\sim 5 \mathrm{~mm}$; gneiss $30 \mathrm{~km}$ east of Caxambu; d) Retro-eclogite with garnet (lower right hand side), greenish brown amphibole (grey on photo) and symplectitic intergrowth of diopside and plagioclase; note the narrow corona of plagioclase around garnet; PPL; width of view $1 \mathrm{~mm} ; 15 \mathrm{~km}$ SE of Andrelândia. e) S-C planes and asymmetric foliation fish in quartz micaschist, indicating sinstral sense of shear; CPL; width of view $10 \mathrm{~mm} ; 10 \mathrm{~km}$ north of Ibitipoca; f) Asymmetric mica fish in mylonite; the dextral shear sense is also indicated by stair stepping and by the oblique quartz fabric; Jesuania shear zone (Fig. 3) 


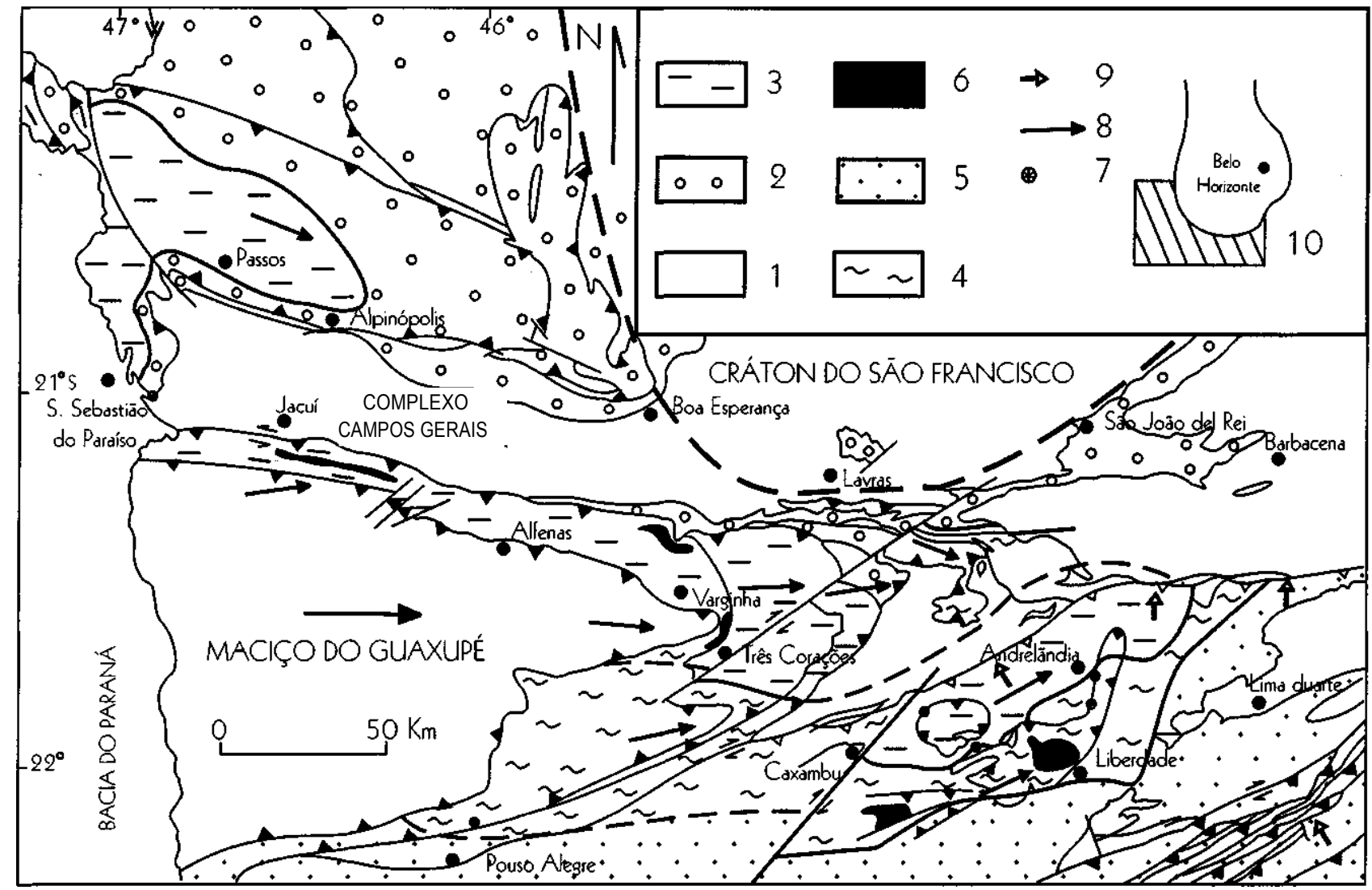

Figura 5 - Mapa metamórfico simplificado: l- embasamento pré $1.8 \mathrm{Ga}$; 2-facies xisto verde; 3- cianita, 4- cianita e sillimanita, 5- sillimanita em facies anfibolito, 6-facies granulito com cianita e K-feldspato, 7- retro-eclogitos; direção de transporte tectônico relacionado a; 8- Faixa Móvel Brasília e 9- Faixa Móvel Ribeira 10-Localização em relação ao Cráton do São Francisco. Inclui dados de Trouw et al (1986), Simões et al (1988), Vasconcellos \& Campos Neto (1988), Heilbron (1993), Valeriano (1993), Junho (1995) e Simões (1995).

Figure 5 - Simplified metamorphic map; 1- pré 1.8 Gabasement; 2- greenschist facies; 3- kyanite;4-kyanite andsillimanite; 5- sillimanite, inamphibolitefacies; 6- high pressure granulites (kyanite + k-feldspar); 7- retro-eclogite; direction of tectonic transport related to; 8 - Brasília Mobile Belt and 9- Ribeira Mobile Belt; 10- location with relation to São Francisco Cráton. Includes data from Trouw et al. (1986), Simões et al. (1988), Vasconcellos \& Campos Neto (1988), Heilbron (1993), Valeriano (1993), Junho (1995) e Simões (1995).

Caxambu (Fig. 5). Estas rochas máficas são compostas de clinopiroxênio, granada, anfibólio, rutilo, quartzo e, por vezes, algum plagioclásio secundário. Os primeiros tem até cerca de $20 \%$ de componente jadeítico, indicando o limite entre diopsídio e onfacita. Entretanto, as estruturas simplectíticas entre diopsídio e plagioclásio (Fig. 4d) e a ausência de plagioclásio na associação metamórfíca principal, revela seu caracter retro-eclogítico. Determinações geotermo-barométricas indicam pressões entre 12 e $15 \mathrm{~kb}$ com temperaturas entre $670^{\circ}$ e $740^{\circ} \mathrm{C}$ para formação destas rochas. Retro-eclogitos já tinham sido descritos em São Sebastião do Paraíso (Schmidt, 1983) e a nordeste de Pouso Alegre (Choudhuri et al. 1978, Hoppe et al. 1985). Todas estas ocorrências localizam-se próximas ou ao longo de falhas de empurrão associadas a DB. Este fato, juntamente com idades radiométricas de $604 \pm 16$ Ma (Trouw \& Pankhurst 1993) e a posição próxima a granulitos no gráfico PT, permitiu interpretá-los como produtos de $\mathrm{M}_{\mathrm{B}}$.

Apesar do $\mathrm{M}_{\mathrm{B}}$ ter alcançado a facies granulito, aparentemente a anatexia associada foi limitada, sendo reconhecidos apenas leucossomas de espessura centimétrica a decimétrica. Como o caminho PT-t durante $\mathrm{M}_{\mathrm{B}}$ passa pelo campo de alta pressão (eclogitos) a água necessária para fusão parcial possivelmente foi expulsa antes de alcançar a temperatura mínima de fusão parcial, o que deve ter inibido a formação de leucossomas expressivos.

Estruturas e metamorfismo relacionados a Faixa Móvel Ribeira Especialmente no domínio III, ocorrem estruturas tectônicas e minerais metamórficos brasilianos, interpretados como mais novos do que os produzidos durante $M_{B}$ e $D_{B}$. Eles serão referidos como $D_{R}$ e $M_{R}$, relacionados a Faixa Móvel Ribeira. Os principais argumentos a favor da interpretação de uma superposição de estruturas e metamorfismos, em parte já mencionados em Trouw et al. (1994) são os seguintes: (i) a isograda de sillimanita (Fig. 5) trunca estruturas sin-Mfi e é subparalela a Faixa Móvel Ribeira; (ii) o crescimento de sillimanita posterior a cianita do $M_{B}$ (sin$\mathrm{D}_{\mathrm{B}}$ ); (iii) a presença de estruturas tardias, com indicadores cinemáticos de transporte tectônico para $\mathrm{NW}$, ortogonal a estruturas mais antigas $\mathrm{D}_{\mathrm{B}}$ e (iv) zonas transpressivas, deslocando estruturas $\mathrm{D}_{\mathrm{B}}$ e isogradas $\mathrm{M}_{\mathrm{B}}$. Este novo episódio termo-tectonico, que embora superposto, possivelmente sucede em continuidade aquele da Faixa Móvel Brasília, será carcaterizado a seguir.

ESTRUTURAS DR Podem ser subdivididas em dois grupos, o primeiro $\left(D_{R 1}\right)$, resultou de um cisalhamento de topo para NNW e o segundo $\left(\mathrm{D}_{\mathrm{R} 2}\right)$, de uma compressão E-W. 
Estruturas $\mathrm{D}_{\mathrm{R} 1}$ ocorrem principalmente no domínio III e deformam a foliação antiga DB. São reconhecidas como zonas de cisalhamento que mergulham em torno de $45^{\circ}$ para S SE e têm lineações na direção do mergulho. Nos milonitos associados, planos S-C e peixes assimétricos de foliação (Fig. 4f) indicam transporte tectônico de topo para NNW (Gonçalves 1987, Bittar 1989, Nummer 1991). Ocorrem ainda dobras assimétricas com vergencia na mesma direção e prováveis reativações de falhas de empurrão $D_{B}$.

$\mathrm{O}$ segundo grupo de estruturas, $\mathrm{D}_{\mathrm{R} 2}$ ocorre na região toda e foi descrito como $\mathrm{D}_{3}$ em trabalhos anteriores (eg. Trouw et al. 1986, Ribeiro et al. 1990, Heilbron 1993). Representa uma compressão E-W que gerou zonas de cisalhamento NE-SW subverticais, destrais, além de dobras e crenulações com eixo $\mathrm{N}-\mathrm{S}$ e superfícies axiais Íngremes. Estas zonas de cisalhamento (Fig. 3a) contêm milonitos característicos, em consequência da deformação praticamente pós-metamórfíca (tanto $\mathrm{M}_{\mathrm{B}}$, como $\mathrm{M}_{\mathrm{R}}$ ). As lineações associadas são subhorizontais, exceto na zona de cisalhamento de Jesuania, onde tem caimento entre $30^{\circ}$ e $40^{\circ}$ para WSW. Neste caso, indicam que o bloco sul desceu em relação ao bloco norte, mostrando que $D_{R 2}$ produziu estruturas desvinculadas de $D_{R}$, pois refletem campos de stress distintos. As estruturas $\mathrm{D}_{\mathrm{R} 2}$ correspondem também às zonas de cisalhamento transcorrentes, características da Faixa Móvel Ribeira (Heilbron 1993, 1995, Voucher et al. 1992, entre outros).

METAMORFISMO MR A distinção entre $\mathrm{M}_{\mathrm{B}}$ e $\mathrm{M}_{\mathrm{R}}$ se baseia, principalmente, no crescimento tardio de sillimanita, que ocorre em todo domínio III e numa faixa estreita dos outros domínios (Fig. 5), associada a $\mathrm{D}_{\mathrm{R} 1}$. Outros minerais tardios atribuídos a MR são cloritóide, muscovita, biotita, hornblenda e cordierita. $\mathrm{O}$ aparecimento de cloritóide, mineral diagnóstico da facies xisto-verde, logo ao norte da isógrada de sillimanita (Fig. 5), indica que esta isógrada corresponde, aproximadamente, a transição entre as facies xisto-verde e anfibolito, num regime de pressão entre 3 e 5 kbar. Somente neste regime de pressão a sillimanita se aproxima da facies xisto-verde (cf. Yardley 1989) Em poucos lugares foi encontrada, ainda, granada pós- $\mathrm{M}_{\mathrm{B}}$, atribuída portanto a $\mathrm{M}_{\mathrm{R}}$ (eg. a sudeste de São João dei Rei; Noce 1987).

Em contraste com $\mathrm{M}_{\mathrm{B}}, \mathrm{M}_{\mathrm{R}}$ produziu dezenas de corpos leucograníticos, autóctones (diatexitos) e intrusivos. Resultam de anatexia e são do tipo $\mathrm{S}$ com tendência metaluminosa e com granada, muscovita, biotita e turmalina (Almeida \& Junho 1994, Junho 1995). Segundo estes autores a anatexia ocorreu em torno de $5 \mathrm{kbar}$, com temperaturas de $650^{\circ}$ a $750^{\circ} \mathrm{C}$. Interpretamos a maioria destes corpos como sin a pós-tectonicos em relação a $\mathrm{D}_{\mathrm{R} 1}$.

IDADES RADIOMÉTRICAS A idade do metamorfismo $\mathrm{M}_{\mathrm{B}}$ e do tectonismo $\mathrm{DB}$ associado ainda é controversa. Heilbron et al. (1989) publicaram cinco isolinhas de referência ( $\mathrm{Rb}-\mathrm{Sr}$, rocha total) com valores entre 1200 e $800 \mathrm{Ma}$ e uma isócrona verdadeira de $636 \pm 34 \mathrm{Ma}$. Na época, os autores interpretaram estes dados como indicativos de um termotectonismo Uruaçuano (Almeida \& Hasui 1984), que correspondaria a $\mathrm{M}_{\mathrm{B}}$. Vasconcellos (1988) e Campos Neto et al. (1990) também advogaram uma idade Uruaçuana para $M_{B}$, principalmente por causa de uma isócrona Rb-Sr de $1397 \pm$ $84 \mathrm{Ma}$, obtida no granito-gnaisse Taguar, supostamente intrusivo em unidades da CDA. Posteriormente, Trouw \& Pankhurst (1993) publicaram cinco idades isocronicas $\mathrm{Sm}-\mathrm{Nd}$, de granadas versus rocha total, de retro-eclogitos e granulitos de alta pressão. A média destas idades, $604 \pm 16 \mathrm{Ma}$, com seus erros respectivos, foi considerada pelos autores como a idade de $\mathrm{M}_{\mathrm{B}}$. Estas idades, junto com dados de campo, a nosso entender datam o metamorfismo principal (MB). Portanto, consideramos que não existem provas inequívocas para um evento Uruaçuano vinculado ao termo-tectonismo que afetou as sucessões do CDA (vide também Trouw \& Pankhurst, 1993). A única idade uruaçuana de boa qualidade é a do granito-gnaisse Taguar, mas este corpo, provavelmente, é uma fatia de embasamento retrabalhado (MB), inserida tectonicamente entre sucessões do CDA, como acontece também na região de Lambari (Oliveira Castro \& Trouw 1996).

Söllner \& Trouw (no prelo) dataram zircões de um quartzoxisto da CDA, com o método U-Pb. Os zircões analisados definem uma discórdia que intercepta a concórdia em $1872 \pm$ $11 \mathrm{Ma}$ e $567 \pm 11 \mathrm{Ma}$. A primeira é interpretada como idade da fonte do sedimento (embasamento) e a segunda, relacionada a $\mathrm{M}_{\mathrm{R}}$, pelos motivos explicados a seguir. N. Machado et al. (no prelo), dataram, com o método $\mathrm{U}-\mathrm{Pb}$, granitos e metassedimentos aflorantes ao longo de um perfil NW-SE, desde Lima Duarte até a costa atlântica. Definiram essencialmente dois eventos metamórfícos, um entre 590 e 565 Ma e outro entre 535 e $520 \mathrm{Ma}$ (este só registrado na parte SE, próximo a costa), além de valores na faixa entre 611 e 604 Ma. Consideramos que $\mathrm{M}_{\mathrm{B}}$ corresponde a faixa de valores entre 611 e 604 Ma pela coincidência com a idade de 604 Ma obtida por Trouw \& Pankhurst (1993) em granadas que cresceram durante $\mathrm{M}_{\mathrm{B}}$. Já o episódio $\mathrm{M}_{\mathrm{R}}$ deve coincidir com o intervalo 590-565 Ma, pois os zircões analisados por Söllner e Trouw indicam uma idade de $567 \mathrm{Ma}$.

CONCLUSÕES Bacias Proterozóicas $\mathrm{Na}$ borda sul do Cráton do São Francisco foram reconhecidas três bacias deposicionais proterozóicas: São João dei Rei, Carandaí e Andrelândia, cada uma com história tectono-sedimentar e paleogeografia distinta.

A Bacia São João dei Rei (1,8 - 1,3 Ga), intracratônica, é caracterizada por sucessões quartzíticas basais que registram eventos transgressivos, com correntes dominantes para NE, subparalelelas a paleocosta local. O soerguimento do embasamento e cobertura a sul, provocou a progressiva continentalização, com a instalação de um sistema fluvial acima das sucessões basais e culminou com a intrusão de diques básicos e basculhamento de todo o pacote. Formou-se então a Bacia Carandaí, inicialmente uma depressão ou meio-graben, paralela a borda da antiga bacia.

A Bacia Carandaí (1 ,3 -1,0 Ga) se caracteriza por depósitos pelágicos e debritos de borda de bacia no setor do graben. Estes sedimentos foram gradativamente sendo substituídos para o topo por pelitos carbonáticos, margas e calcários, que mostram a expansão de um mar raso e de águas quentes na antiga depressão e sobre o embasamento.

A Bacia Andrelândia (1 ,0 - 0,6 Ga) é uma bacia de margem passiva, cuja borda, de orientação NW-SE, foi produzida por um novo soerguimento, agora modificando a antiga pendente regional do embasamento, de $\mathrm{N}$ para $\mathrm{SW}$ e resultando no estabelecimento do Alto de Ibertioga. A reconstrução estrutural e metamórfica das sucessões permitiu a caracterização de seis associações de litofacies, distribuídas em distintos domínios tectônicos, autóctones e alóctones. Após a deposição das sucessões fluviais basais, contendo detritos oriundos da desnudação do embasamento (associação 1), segui-se um riftea- 
mento incipiente, acompanhado de magmatismo básico, que facilitou a transgressão marinha na bacia. Este processo (associações 2 a 4), esta representado por um trato de sistema transgressivo caracterizado por parasequências depositadas em arcabouço retrogradacional (xistos, quartzitos; associação 2), por empilhamento de parasequências formando uma rampa quartzítica (associação 3) e culmina com a inundação da rampa e deposição de pelitos em duas etapas, separadas por breves oscilações do mar (associação 4). Em seguida, ocorreu um período de mar baixo, devido a instalação de geleiras no continente próximo, com formação de aprons e turbiditos (base da associação 5). A subida glacio-eustática do mar promoveu nova sedimentação pelítica (biotita-xistos homogéneos de topo na associação litofacial 5).

As etapas de subida do nivel do mar correspondentes às associações 4 e 5 também inundaram as áreas a norte do Alto de Ibertioga, formando lagunas e prováveis estuários. Provavelmente a associação 5 corresponda com a plataforma carbonática (Bambuí) desenvolvida acima do cráton. Finalmente, a associação 6 , que representa os tempos 2 a 5 no fundo da bacia, é caracterizada por sedimentação pelítica constante, interrompida apenas por fluxos turbidíticos diluídos e por efusões básicas de fundo de bacia, com assinutura transicional à oceânica.

A evolução destas bacias abrange o lapso 1,8 -0,6 Ga, valores correspondentes as idades mais novas no embasamento e ao primeiro episódio metamórfico Brasiliano, respectivamente.

A BSJR, mais antiga e de caracter intracratônico, foi gerada por adelgaçamento crustal, provavelmente contemporâneo à formação da Bacia Espinhaço, situada a norte. No entanto, na região considerada, não existem registros de um rifteamento inicial. A história deposicional na BSJR começa com a transgressão de um mar plataformal raso sobre embasamento desnundado e saprolitizado e continua com a sedimentação de arenitos maturos em áreas litorâneas, com lagunas, barreiras e praias (Ciclo Deposicional Tiradentes e parte basal do Ciclo Deposicional Lenheiro). As paleocorrentes dominantes se orientavam para NE paralelas a costa local. Oscilações do nível do mar produziram discordâncias intraformacionais e refletem instabilidade tectônica precursora de um rifteamento que levantou setores do embasamento e sua cobertura ao sul do paralelo de São João dei Rei. Este levantamento gerou uma pendente para norte, cada vez mais pronunciada, resultando na instalação de um sistema fluvial entrelaçado, incialmente arenoso e depois conglomerático (parte superior do Ciclo Deposicional Lenheiro). O rifteamento culminou com a intrusão de diques básicos e o basculhamento das sucessões da BSJR. Formou-se então a Bacia Carandaí, inicialmente uma depressão ou meio-graben, paralela a borda da antiga bacia.

O estabelecimento do graben facilitou uma nova invasão marinha, que produziu a sedimentação pelítica no fundo e diamictitos nas suas bordas. Depois deste preenchimento, seguiu-se a deposição de calcários, margas e pelitos carbonáticos, que mostram a expansão de um mar raso de águas quentes sobre o embasamento. A sucessão siliciclástica fina acima dos calcários, preservada ao norte de Lavras, registra o ápice da expansão do mar Carandaí.

O fechamento da Bacia Carandaí pode ter resultado de um novo soerguimento do embasamento ao sul do paralelo de São João dei Rei. Este tectonismo produziu uma mudança da pendente regional do embasamento, de $\mathrm{N}$ para SW, resultando na formação da borda primitiva da BA, de orientação geral
NW-SE. A distribuição vertical e lateral das associações de litofacies representantes de cada uma das etapas da evolução sugerida para a Bacia Andrelândia (Fig. 2), permite interpretala como uma bacia de margem passiva (Paciullo et al. 1993). Estas etapas foram reconhecidas em distintos domínios tectônicos, definidos em função do termo-tectonismo brasiliano. No domínio autóctone (I, Fig. 1), ocorrem associações de facies que representam regiões próximas ao continente, enquanto grande parte das associações de fundo de bacia ocorrem nos domínios alóctones (II e III).

A primeira etapa deposicional na Bacia Andrelândia é interpretada como fluvial (associação litofacial; Fig. 2), sendo os materiais detríticos oriundos da desnudação do embasamento. A esta etapa associaram-se efusões de lavas básicas continentais, provavelmente devido à rifteamento incipiente do embasamento. Este tectonismo não só realçou a borda da bacia, definindo o Alto de Ibertioga, mas também facilitou a primeira deposição marinha na bacia. Esta é representada por um trato de sistema transgressivo (associação 2), caracterizado por sucessivas parasequências dispostas num arcabouço retrogradacional, devido a progressivos avanços e recuos de um mar raso, que retrabalhava os sedimentos fluviais ainda aportados desde o Alto de Ibertioga. A transgressão culminou com a formação de uma ampla plataforma de tipo rampa (= associação 3). Os quartzitos de Ibitipoca e Carrancas são o registro de facies próximas à borda da bacia e constituem conjuntos agradacionais de parasequências de tipo "stranded" (Van Wagoner et al. 1990). As facies mais fundas da época (quartzitos, pelitos) aparecem em Luminárias e São Tomé das Letras. Acima da rampa aconteceu um processo transgressivo (4), registrado por duas etapas de ascenso do mar com deposição de pelitos, separadas por breves oscilações do mar ou até detenções na sedimentação (parasequências em esquema retrogradacional fraco).

Em seguida, ocorreu um período de mar baixo, glacial, com formação de aprons turbidíticos e fluxos de detritos nas áreas próximas ao Alto de Ibertioga e de turbiditos no setor marinho fundo. Este período, representado pela base da associação 5, corresponderia a sedimentação glaciogênica Jequitaí-Macaubas. $\mathrm{O}$ ascenso glacio-eustático do nível do mar deu origem a sucessão de topo da associação 5 (biotita-xistos homogéneos).

Cabe salientar que, com as etapas de ascenso do mar registradas pelas associações 4 e 5 , a região ao norte do Alto de Ibertioga foi inundada, formando lagunas, talvez associadas a estuários. Ressaltamos também que durante a última etapa de transgressão toda a região foi afogada e, por isto, provavelmente, a facies de topo da associação 5 se corresponda com a plataforma então estabelecida acima do cráton, a norte (= calcários e pelitos Bambuí). Entretanto, no fundo da bacia, a SW, continuava a sedimentação pelítica (associação 6), periodicamente interrompida pelas efusões básicas de assinatura transicional ou oceânica.

Evento Termo-Tectônico Brasiliano As análises estrutural, metamórfica e microtectônica mostram que as sequências estudadas participaram de sucessivos episódios de deformação e metamorfismo brasilianos. O episódio mais antigo, $\mathrm{DB}$, ocorreu em torno de $600 \mathrm{Ma}$ e produziu transporte tectônico de topo para leste. Resultou um conjunto de nappes e escamas tectônicas (nappes de Luminárias, Liberdade e Passos), geralmente com corpos ultramáficos na base. O metamorfismo associado, $\mathrm{M}_{\mathrm{B}}$, foi de pressão relativamente elevada, atingindo a facies granulito no campo de estabilidade da 
cianita e formando também rochas eclogíticas. Este episódio corresponde a colisão entre o Maciço do Guaxupé e o protocráton do São Francisco, que na época se extendia mais para SE. É aqui considerado como equivalente ao que produziu a Faixa Móvel Brasília.

Um novo episódio tectônico, $\mathrm{D}_{\mathrm{R} 1}$, provavelmente ao redor de $570 \mathrm{Ma}$, resultou em encurtamento crustal com transporte para NNW, acompanhado de dobramento em escala regional. $\mathrm{O}$ metamorfísmo associado, $\mathrm{M}_{\mathrm{R}}$, foi de pressão mais baixa que o anterior, sendo caracterizado pela presença de sillimanita, cordierita e numerosos corpos graníticos anatéticos. Final- mente, uma nova compressão E-W gerou zonas de cisalhamento transpressionais subverticais, de orientação NE-SW e com sentido de movimento destral $\left(\mathrm{D}_{\mathrm{R} 2}\right)$. Estes dois últimos episódios podem ser relacionados a Faixa Móvel Ribeira.

AGRADECIMENTOS Os autores agradecem ao CNPq, FINEP e PADCT pelos auxílios à pesquisa. R.A. J.Trouw e R.R. Andreis são bolsistas do CNPq. Os autores são gratos também aos alunos de graduação e pós-graduação do Departamento de Geologia da UFRJ que participaram dos trabalhos de campo.

\section{REFERÊNCIAS}

ALMEIDA, F. F. M. 1977. O Cráton do São Francisco. Rev. Bras. Geoc., 7: 349-364.

ALMEIDA, F.F.M.; HASUI, Y. 1984. O embasamento da Plataforma Sul Americana. In: O Precambriano do Brasil, p. 1-5. Ed. Edgard Blucher, São Paulo, 378p.

ALMEIDA, J.C.H. 1992. Mapeamento geológico da Folha Luminárias-MG (1:50.000), com ênfase na análise estrutural dos metassedimentos do Ciclo Deposicional Andrelândia. Tese de Mestrado, IGEO-UFRJ, Rio de Janeiro, $102 \mathrm{p}$.

ALMEIDA, S. 1992. Petrografia e geoquímica das rochas ultramáficas na região de Liberdade e Carrancas, Minas Gerais. Tese Mestrado, IGEOUFRJ, Rio de Janeiro, 166p.

A1MEIDA, M.; JUNHO, M.C.B. 1994. Leucogranito Capivara e suas encaixantes migmatíticas, Itamonte, Sul de Minas Gerais, $38^{\circ}$ Congr. Bras. Geol., Camboriu, SC, Boi. Rés. 3, 78-79.

ANDREIS, R. R.; RIBEIRO, A.; PACIULLO, F. V. P. 1989a. Ciclos Deposicionais no Proterozóico das Folhas Barbacena e Divinópolis (setor sul)

1 :250.000. In: ISIMP. GEOL. SUDESTE, Rio de Janeiro, 1989. Resu-

mos.... Rio de Janeiro, SBG, p. 97-98.

ANDREIS,R. R.; PACIULLO,F. V.P.; RIBEIRO, A. 1989b.Caracterização preliminar de Ciclos Deposicionais Proterozóicos do Sudeste de Minas Gerais (Folhas Barbacena e Divinópolis, 1 :250.000). In: I SIMP. GEOL. SUDESTE, Rio de Janeiro, 1989. Resumos... Rio de Janeiro, SBG, p. 101-102.

ÁVILA, C. A. 1992. Geologia, Petrografia e Geoquímica das rochas Précambrianas (unidade metadioritica Itutinga e unidade metatrondjemítica Caburú) intrusivas nas rochas do Greenstone Belt Barbacena, São João dei Rei, Minas Gerais. Tese de Mestrado, IGEO - UFRJ, Rio de Janeiro, $268 \mathrm{p}$

BARBOSA, O. 1954. Évolution du géosynclinal Espinhaço. In : INTER. GEOL. CONGR. 19, Alger, 1952, Comptes Rendus, Alger, sec. 13, fase. 14, p. 17-36.

BRANDALISE, L. A. et al 1991. Folha Barbacena, SF.23-X-C-III, 1:100.000, Estado de Minas Gerais. Progr. Levantamentos Geológicos Básicos. Brasília, DNPM/CPRM, 162 p.

BITTAR, S. M. B. 1989. Mapeamento geológico-estrutural da Folha Caxambu e da parte sul da Folha Luminárias. Tese de Mestrado, IGEO-UFRJ, Rio de Janeiro, $226 \mathrm{p}$.

BRITO NEVES, B. B. 1992. O Proterozóico Médio no Brasil: ensaio do conhecimento e seus problemas. Rev. Bras. Geol., 22 (4): 449 - 461.

CAMPOS NETO, M. da COSTA; PERROTTA, M. M.; PELOGGIA, A. U. G. 1990. A porção ocidental da Faixa Alto Rio Grande (SP-MG). In: CONGR. BRAS. GEOL., 36, Natal, 1990. Anais.... SBG, 6,2615 - 2630.

CHRISPIM, S. J. 1983. Dados preliminares sobre a geologia estrutural das Serras da Bocaina e Faria, Lavras, MG. In : SIMP. GEOL. MINAS GERAIS, 2, Belo Horizonte. Anais.., SBG-MG, bol.3, 376 - 386.

CHOUDHURI, A.; FIORI, A.P.; WINTERS, A.A.M.; BETTENCOURT, J.S. \& RODRIGUES, J.E. 1978. A note on small bodies of ecoglite as inclusions in high grade gneisses north of Pouso Alegre, Minas Gerais. Rev. Bras. Geocienc. 8: 63-68.

COBBOLD \& QUINQUIS, 1980. Development of sheath folds in shear regimes. Journal of Structural Geology, V2, N 1/2: 119-126.

COUTINHO, J. M. V. 1968.0 gnaisse alcalino da Serra do Matola. Cadeira de Mineralogia e Petrologia n 15, Boletim n 292, Fac. Filosofia, Ciências e Letras, USP, São Paulo, 135 p.

DEL LAMA, E. A; OLIVEIRA, M.A.F. \& ZANARDO, A. 1993. Geotermobarometria aplicada a rochas do sul do Complexo Campos Gerais. In: SIMP. GEOL. MINAS GERAIS, VII, Belo Horizonte, 1993, Boi. 12: 93-94.
EBERT, H. 1957. Beitrag zur Gliederung des Prãkambriums in Minas Gerais. Geol. Rundschau, 45,471-521.

EBERT, H. 1963.The Manganese-bearing Lafaiete Formation as a guidehorizon in the pre-cambrian of Minas Gerais. An. Acad. Bras. Ciências, 35: 545-559.

EBERT, H. 1971. Os Paraibides entre São João dei Rei, MG, e Itapira, SP, e a bifurcação entre Paraibides e Araxaídes. Publicado "in memoriam" in: SBG-SP, Publ. 12/1984, 72-103.

GONÇALVES, M. L. \& FIGUEIREDO M.C.H. 1992. Geoquímica dos anfibolitos de Santana do Garambéu, MG: implicações sobre a evolução do Grupo Andrelândia. Geochim. Brasil., 6 (2): 127-140.

GONCALVES, M. L. 1987. Geologia da área de Santana do Garambéu, sul de Minas Gerais Tese de Mestrado, IGEO-UFRJ, Rio de Janeiro, 176 P-

HATCHER Jr, R. D. \& HOOPER, R. J. 1992. Évolution of crystalline thrust sheets in internai parts of mountain chains. In: McCLAY, K.R. ed. Thrust Tectonics. Chapman \& Hall, $447 \mathrm{p}$.

HASUI, Y. \& OLIVEIRA, M.A.F. 1984. Província Mantiqueira, Setor Central. In: O Pré-Cambriano do Brasil, Almeida \& Hasui coordenadores. Ed. Edgard Blucher 378p.

HEILBRON, M. 1984. Evolução metamórfica-estrutural da área entre Itutinga e Madre de Deus de Minas Gerais, MG. Tese de Mestrado, IGEO/UFRJ, Rio de Janeiro, $151 \mathrm{p}$.

HEILBRON, M. 1985.0 metamorfísmo da área de Itutinga - Madre de Deus de Minas, MG. SIMP. GEOL. MINAS GERAIS, 3, SBG-MG, Belo Horizonte, Boi. 5: 219-234.

HEILBRON, M. 1993. Evolução Tectono-metamórfica da seção Bom Jardim de Minas (MG) -Barra do Piraí (RJ), Setor Central da Faixa Ribeira. Tese de Doutorado, USP, SP, $268 \mathrm{p}$.

HEILBRON M.; GONÇALVES, M. L; TEIXEIRA, W.; TROUW, R. A. J ; KAWASHITA, K.; PADILHA, A. V. 1989. Geocronologia da área entre Lavras, São João dei Rei, Lima Duarte e Caxambu. An. Acad. Bros. Ciências., 61 (2): 177-199.

HOPPE, A.; KLEIN, H.; CHOUDHURI, A. \& SCHMIDT, W. 1985. Eclogitos pré-cambrianos no sudoeste de Minas Gerais, SIMP. GEOL. MINAS GERAIS, 3, Anais,.., p.180-192.

HETTICH, M. 1977. A glaciação proterozóica no centro-norte de Minas Gerais. Rev. Bras. Geoc., 7(2): 87-101.

ISSOTA, C.A.; ROCHA-CAMPOS, A.C. \& YOSHIDA, R. 1969. Striated pavement of the upper precambrian glaciation in Brazil. Nature 22(5192): 466-468, London.

JUNHO, M.C.B. 1995. Leucogranites and Related Migmatites, Southern Minas Gerais and Southwestern Rio de Janeiro States, Brazil. An. Acad. Bras. Cienc. 67(4):497-515.

JUNHO, M. C. B.; DEHLER, N. M.; XAVIER, E. M. \& CAPUANO, C. S. 1991. Geologia preliminar da região entre Aiuruoca e Alagoa, sul de

MG. In: SIMP. GEOL. MINAS GERAIS, 6, Ouro Preto, MG. Resu-

mos..., SBG/MG, p. 64-67.

KARFUNKEL, J. \& NOCE, C. M. 1983. Desenvolvimento faciológico do Pré-Cambriano superior da região de Carandaí-São João dei Rei, Minas Gerais. In : SIMP. GEOL. MINAS GERAIS, 2, Belo Horizonte. Anais..., SBG/MG, bol.3, p. 16-29.

MACHADO FILHO, L.; RIBEIRO, M. W.; GONZALES, S. R.; SCHENINI, C. A.; NETO, A. S.; PALMEIRA, R. C. B.; PIRES, J. L.; TEIXEIRA, W.; CASTRO, H. E. F. 1983. Geologia. In: DNPM Proj. RADAMBRASIL Folhas SF-23 Rio de Janeiro e SF-24 Vitória, Rio de Janeiro (Levantamento de Recursos Naturais), 32, $773 \mathrm{p}$. 
MACHADO, N.; SCHRANK, A.; ABREU, F.R.; KNAUER, I.G.; ALMEIDA-ABREU, P.A. 1989. Resultados preliminares de geocronologia U/Pb na Serra do Espinhaço Meridional. Boi. SBG-MG 10: 171-174.

MACHADO, N. \& NOCE, C.M. 1993. A evolução do setor sul do Cráton do São Francisco entre 3,1 e 0.5 Ga baseada em geocronologia U-Pb. In: SIMP. CRÁTON DO SÃO FRANCISCO, 2, Salvador, 1993 Anais... Salvador, p. 100-102.

MACIEL,M 1985. Geologia estrutural da Serra de Três Pontas, MG. Dados preliminares. In: SIMP. GEOL. MINAS GERAIS, 2, Belo Horizonte. Anais... Belo Horizonte, SBG-MG, bol.3, p.402-410.

MAGALHÃES, A. C. M. 1985. Geologia de corpos ultramáflcos da região entre São João dei Rei e Liberdade, com ênfase especial na área de Carrancas, MG. Tese de Mestrado, UFRJ-IGEO, Rio de Janeiro, 177 $\mathrm{P}$ -

MITCHUM, R. M. 1977. Seismic stratigraphy and global change of sea levei, Part 1: Glossary of terms used in seismic stratjfgraphy. In: C. E. PAYTON, ed., Sceismic stratigraphy-aplication to hidrocarbon exploration: AAPG Memoir 26, p. 205-212.

NOCE, C. M. 1987. Estudo geológico-estrutural do Grupo São João dei Rei na região de Tiradentes-Barroso -Barbacena, MG e considerações sobre seu embasamento.Tese Mestrado, UFRJ-IGEO, Rio de Janeiro, $156 \mathrm{p}$.

NUMMER, A. R. 1991. Análise estrutural e estratigrafia do Grupo Andrelândia na região de Santa Rita do Ibitipoca-Lima Duarte, sul de Minas Gerais. Tese de Mestrado, IGEO-UFRJ, Rio de Janeiro, $191 \mathrm{p}$

OLIVEIRA CASTRO, E. M.; BARONE, M. 1994. Metamorfismo invertido da área de Carvalhos - Liberdade -Arantina (MG). Estágio de Campo IV, Relatório inédito. Dept. Geologia, IGEO-UFRJ, Rio de Janeiro, 48p.

OLIVEIRA CASTRO, E.M.; TROUW, R.A.J. (no prelo) Cinemática de falhas de empurrão na região de Lambari (MG) no contexto da interferência entre as Faixas Brasília e Ribeira In: CONG. BRAS. GEOL., 39, Salvador, 1996. Anais...,SBG

PACIULLO, F. V. P. 1980. Mapeamento geológico-estrutural da área de Minduri, $M G$. Tese de Mestrado IGEO-UFRJ Rio de Janeiro, 80 p.

PACIULLO, F. V. P. 1992. Orto-anfibolitos no Ciclo Deposicional Andrelândia: composição química e ambiente tectônico. In: CONGR. BRAS. GEOL., 37, São Paulo, 1992. Boi. res.exp..., São Paulo, vol. 2, p. 28-29.

PACIULLO, F. V. P.; RIBEIRO, A.; ANDREIS, R. R. 1993. Reconstrução de uma Bacia fragmentada: o caso do Ciclo Deposicional Andrelândia. In: SIMP. CRÁTON DO SÃO FRANCISCO, 2, Salvador, 1993. Anais.., Salvador, 224-226.

PINTO, C. P.; BRANDALISE, L. A.; VIANA, H. S.; BRUNO, E. M. 1992. Suíte metamórfica São Bento dos Torres, Serra da Mantiqueira - MG. REM: R. Esc. de Minas, Ouro Preto, 45 (1 e 2): 187-189.

PASSCHIER, C.W.; TROUW, R.A.J.; ZWART, H.J.; VISSERS, R. L.M. 1992. Porphyroblast rotation: eppur si muove? Jour. Metamorphic Geology 10, 283-294.

PASSCHIER, C.W. \& TROUW, R.A.J. (1996) Microtectonics. SpringerVerlag, Berlin Heidelberg New York

PIRES, F. R. M. 1977. Geologia do Distrito Manganesifero de Conselheiro Lafaiete, Minas Gerais. Tese de Mestrado, IG-UFRJ, Rio de Janeiro, RJ, $344 \mathrm{p}$.

PIRES, F.R.M. 1978. The Archean Barbacena greenstone belt in it's typical development and the itabirite distribution at the Lafaiete District. $A n$. Acad. Bras. Ciênc., 50: 599-600.

RIBEIRO, A. 1980. Mapeamento geológico-estrutural da área de Itumirim, Minas Gerais. Tese de Mestrado, IGEO-UFRJ, Rio de Janeiro, 57 p.

RIBEIRO, A.; PACIULLO, F. V. P.; ANDREIS, R. R.; TROUW, R. A. J. HEILBRON, M. 1990. Evolução policíclica proterozóica no sul do Cráton do São Francisco: análise da região de São João dei Rei e Andrelândia, MG. In: CONGR. BRAS. GEOL, 36., Natal, 1990. Anais..., SBG, 6: 2605-2614

RIBEIRO, A.; SILVA, R.R. (no prelo) Possíveis correlações entre bacias proterozócias a sul e sudeste do Cráton do São Francisco, Minas Gerais. In: CONG. BRAS. GEOL., 39, Salvador, 1996. Anais..., SBG.

ROIG, H. L.; SCHRANK, A. 1992. Caracterização da zona de sutura JacuíConceição da Aparecida - Limite norte do Complexo de Guaxupé - MG. $37^{\circ}$ Congr. Brasil. Geol. São Paulo, Boi. Rés. Exp. 283-284.

SCHMIDT, W. 1983. Die Geologie der Araxá Gruppe in Sudwest Minas Gerais, Brasilien unter besonderer Berucksitigung dês Grunsteingurtels von Fortaleza de Minas. Diss. (Msc), 134p. Freiburg I. Br.

SILVA, R. R. 1990. Estratigrafia, metamorfismo e geologia estrutural do Grupo Andrelândia em Carvalhos, sul de Minas Gerais. Tese de Mestrado, IGEO-UFRJ, Rio de Janeiro, 144 p.
SIMÕES , L.S.A.1995. Evolução tectônometamórfica da Nappe de Passos, sudoeste de Minas Gerais, Tese de Doutoramento, IG-USP, São Paulo, $149 \mathrm{p}$.

SIMÕES, L.S.A.; VALERIANO, C.M; MORALES, N.; ZANARDO, A.; MORAES, R. \& GOMI, C.Y. 1988. Zonação metamórfica inversa do Grupo Araxá-Canastra na região de São Sebastião do Paraíso-Alpinópolis, MG. In: CONGR. BRAS. GEOL. 35, Belém, 1988, Anais... SBG 3: $1203-1215$.

SÖLLNER, F.; TROUW, R.A.J. (no prelo) The Andrelândia depositional cycle (Minas Gerais, Brazil), a post-Transamazonic sequence south of the São Francisco craton: evidence from U-Pb dating on zircons of a metasediment. Journal of South American Earth Sciences.

TEIXEIRA, W. 1982. Geochronology of the Southern part of the São Francisco Craton. Rev.Bras. Geoc., 12, (1, 2 e 3): 268-277.

TEIXEIRA, W. 1985. A evolução geotectônica da Porção Meridional do Cráton do São Francisco, com base em interpretações geocronológicas. Tese de Doutoramento, USP, São Paulo, SP, 207 p.

TEIXEIRA, W.; FIGUEIREDO, M. C. H. 1991. An outline of Early Proterozoic crustal evolution in the São Francisco craton, Brazil: a review. Precambrian Research, 53: 1-22.

TEIXEIRA, N. A. 1992. Contribuição à geologia do "Greenstone Belt" Itumirim-Nazareno (MG). In: CONGR. BRAS. GEOL., 37, São Paulo, 1992. Boi. res. exp.., vol.1, p. 476.

TROUW, R. A. J.; RIBEIRO, A.; PACIULLO, F. V. P. 1980. Evolução estrutural e metamórfica de uma área a SE de Lavras, MG. In: CONGR. BRAS. GEOL., 31, Balneário Camboriú, SC, 1980. Anais..., vol.5, Balneário Camboriú, p. 2773.

TROUW, R. A. J.; PACIULlO, F. V. P.; CHRISPIM, S. J.; DAYAN, H. 1982. Análise de deformação numa área a SE de Lavras, Minas Gerais. In: CONGR. BRAS. GEOL., 32, Salvador, 1982. Anais..., Salvador, SBG, vol.1, p. 187-198.

TROUW, R. A. J.; RIBEIRO, A.; PACIULLO, F. V. P. 1983. Geologia estrutural dos Grupos São João dei Rei, Carrancas e Andrelândia, Minas Gerais. Acad. Bras. Ciênc., 55 (1),71-85.

TROUW, R. A. J.; RIBEIRO, A.; PACIULLO, F. V. P.; HEILBRON, M. 1984. Os Grupos São João dei Rei, Carrancas e Andrelândia interpretados como continuação dos Grupos Araxá e Canastra . In: CONGR. BRAS. GEOL., 33, Rio de Janeiro, 1984. vol. 2, p. 3227-3240.

TROUW, R. A. J.; RIBEIRO, A.; PACIULLO, F. V. P. 1986. Contribuição à geologia de Folha Barbacena -1:250.000. In: CONGR. BRAS. GEOL., 34, Goiânia, 1986. Anais..., SBG, v.2, p. 974-984.

TROUW, R. A. J.; PANKHRUST, R. J. 1993. Idades radiométricas ao sul do Cráton do São Francisco: região da Folha Barbacena, Minas Gerais. In: SIMP. CRÁTON DO SÃO FRANCISCO, 2, Salvador, 1993. Anais..., Salvador, p.260-262.

TROUW, R. A.J.; PACIULLO, F. V. P.; RIBEIRO, A. 1994. A Faixa Alto Rio Grande reinterpretada com zona de interferência entre a Faixa Brasília e a Faixa Ribeira. In: GONGR. BRAS. GEOL., 38, Camboriú, SC, 1994. Boi. rés. ex..., SBG, v.3, p. 234-235.

VALERIANO, C. M. 1985. Geologia estrutural e estratigrafia do Grupo São João dei Rei. Tese de Mestrado, UFRJ-IGEO, Rio de Janeiro, 83 p.

VALERIANO, C.M. 1992. Evolução tectônica da extremidade meridional da Faixa Brasília, região da Represa de Furnas, Sudoeste de Minas Gerais. Tese de Doutoramento. IG-USP, São Paulo, 192p.

VALERIANO, C. M.; HEILBRON, M.; SIMÕES, L. S. A. 1994. Compartimentação tectônica da porção meridional da Faixa Brasília nos segmentos de Araxá e da Represa de Furnas, sudoeste de Minas Gerais. In: CONGR. BRAS. GEOL., 38, Balneário Camboriú, 1994. Resumos..., Balneário Camboriú, SBG, 217-219.

VAN WAGONER, J. C.; MITCHUM, R. M.; CAMPION, K. M.; RAHMANIAN, V. D. 1990. Silliàdastic Sequence Stratigraphy in Well Logs, Cores and Outcrops. AAPG Methods in Exploration Series, $\mathrm{n}^{\circ} 7,55 \mathrm{p}$.

VASCONCELOS, A. C. B. C. 1988. O Grupo Andrelândia na região ao norte de Ouro Fino Tese de Mestrado, IG-USP, São Paulo, 168 p.

VOUCHER, A.; TOMMASI, A.; EGYDIO-SILVA, M.; TROMPETTE, R. 1992. Tectônica de escape na terminação de um craton: A Faixa Ribeira. In: CONGR. BRAS. GEOL.; 37. São Paulo, 1992. Boi. Rés. Exp... São Paulo, SBG. V. 2, p.373-375.

YARDLEY, B.W.D. 1989. An introduction to Metamorphic Petrology. Longman Scientific \& Technical, Essex, England. 248p.

MANUSCRITO A863

Recebido em 31 de agosto de 1996 Revisão do autor em 30 de novembro de 1996 Revisã 0 aceita em 15 de janeiro de 1997 